\title{
Sphingosine Kinase 2 Potentiates Amyloid Deposition but Protects against Hippocampal Volume Loss and Demyelination in a Mouse Model of Alzheimer's Disease
}

\author{
Mona Lei, ${ }^{1 \star}$ Jonathan D. Teo, ${ }^{1 \star}$ Huitong Song, ${ }^{1}$ Holly P. McEwen, ${ }^{1}$ Jun Yup Lee, ${ }^{1}$ Timothy A. Couttas, ${ }^{1}$ Thomas Duncan, ${ }^{2}$ \\ Rose Chesworth, ${ }^{3}$ Josefine Bertz, ${ }^{4}$ Magdalena Przybyla, ${ }^{4}$ Janet Van Eersel, ${ }^{4}$ Benjamin Heng, ${ }^{5}$ CGilles J. Guillemin, ${ }^{5}$ \\ Lars M. Ittner, ${ }^{4}$ Thomas Fath, ${ }^{4}$ Brett Garner, ${ }^{6,7}$ Arne Ittner, ${ }^{4}$ Tim Karl, ${ }^{3,8}$ and $®$ Anthony S. Don ${ }^{1,9}$ \\ ${ }^{1}$ Centenary Institute, University of Sydney, Camperdown 2006, New South Wales, Australia, ${ }^{2 B}$ Brain and Mind Centre, Sydney Medical School, University of \\ Sydney, Camperdown 2006, New South Wales, Australia, ${ }^{3}$ School of Medicine, Western Sydney University, Campbelltown 2560, New South Wales, \\ Australia, ${ }^{4}$ Dementia Research Centre, Faculty of Health and Medical Sciences, ${ }^{5} \mathrm{MND}$ Research Centre, Neuroinflammation Group, Macquarie University, \\ Sydney 2109, New South Wales, Australia, ${ }^{6}$ Illawarra Health and Medical Research Institute, ${ }^{7}$ School of Chemistry and Molecular Bioscience, University of \\ Wollongong, Wollongong 2522, New South Wales, Australia, ${ }^{8}$ Neuroscience Research Australia, Randwick 2031, New South Wales, Australia, and ${ }^{9}$ NHMRC \\ Clinical Trials Centre, University of Sydney, Camperdown 2006, New South Wales, Australia
}

Sphingosine 1-phosphate (S1P) is a potent vasculoprotective and neuroprotective signaling lipid, synthesized primarily by sphingosine kinase 2 (SK2) in the brain. We have reported pronounced loss of S1P and SK2 activity early in Alzheimer's disease (AD) pathogenesis, and an inverse correlation between hippocampal S1P levels and age in females, leading us to speculate that loss of S1P is a sensitizing influence for AD. Paradoxically, SK2 was reported to mediate amyloid $\beta(\mathrm{A} \beta)$ formation from amyloid precursor protein (APP) in vitro. To determine whether loss of S1P sensitizes to $A \beta$-mediated neurodegeneration, we investigated whether SK2 deficiency worsens pathology and memory in male J20 (PDGFB-APP ${ }_{\text {SwInd }}$ ) mice. SK2 deficiency greatly reduced A $\beta$ content in J20 mice, associated with significant improvements in epileptiform activity and cross-frequency coupling measured by hippocampal electroencephalography. However, several key measures of $\mathrm{APP}_{\mathrm{SwInd}}$-dependent neurodegeneration were enhanced on the SK2-null background, despite reduced $\mathrm{A} \beta$ burden. These included hippocampal volume loss, oligodendrocyte attrition and myelin loss, and impaired performance in Y-maze and social novelty memory tests. Inhibition of the endosomal cholesterol exporter NPC1 greatly reduced sphingosine phosphorylation in glial cells, linking loss of SK2 activity and S1P in AD to perturbed endosomal lipid metabolism. Our findings establish SK2 as an important endogenous regulator of both APP processing to $A \beta$, and oligodendrocyte survival, in vivo. These results urge greater consideration of the roles played by oligodendrocyte dysfunction and altered membrane lipid metabolic flux as drivers of neurodegeneration in AD.

Key words: Alzheimer's disease; myelin; neuroprotection; oligodendrocyte; sphingosine 1-phosphate; sphingosine kinase

Significance Statement

Genetic, neuropathological, and functional studies implicate both $\mathrm{A} \beta$ and altered lipid metabolism and/or signaling as key pathogenic drivers of Alzheimer's disease. In this study, we first demonstrate that the enzyme SK2, which generates the signaling lipid S1P, is required for A $\beta$ formation from APP in vivo. Second, we establish a new role for SK2 in the protection of oligodendrocytes and myelin. Loss of SK2 sensitizes to $\mathrm{A} \beta$-mediated neurodegeneration by attenuating oligodendrocyte survival and promoting hippocampal atrophy, despite reduced $\mathrm{A} \beta$ burden. Our findings support a model in which $\mathrm{A} \beta$-independent sensitizing influences such as loss of neuroprotective S1P are more important drivers of neurodegeneration than gross $\mathrm{A} \beta$ concentration or plaque density.

\section{Introduction}

Sphingosine 1-phosphate (S1P) is a signaling lipid derived by phosphorylation of the membrane lipid sphingosine, a reaction that is catalyzed by sphingosine kinase 1 or 2 (SK1 or SK2). S1P signals through five G-protein-coupled receptors, S1PR1-S1PR5

agents/analytic tools; M.L., J.D.T., H.S., H.P.M., J.Y.L., T.A.C., T.D., R.C., A.I., T.K., and A.S.D. analyzed data; L.M.I., T.F., B.G., A.I., T.K., and A.S.D. wrote the paper.

This work was supported by National Health and Medical Research Council of Australia (NHMRC) project Grants 1100626 (A.S.D., B.G., T.F.), 1102012 (T.K.), 1141789 (T.K.), 1081916 (L.I., T.K.), 1143978 (A.I.), NHMRC program 
(Choi and Chun, 2013; Rosen et al., 2013), but also has important intracellular functions and binding targets (Hait et al., 2014; Shen et al., 2014). S1P receptor signaling is essential for vascular development and neural tube closure during embryogenesis (Mizugishi et al., 2005), and regulates vascular barrier function and lymphocyte circulation in adults (Rosen et al., 2013; Bigaud et al., 2014). In the nervous system, S1P potentiates glutamate and acetylcholine release from presynaptic terminals (Kajimoto et al., 2007; J. P. Chan et al., 2012a; Riganti et al., 2016). SK2 is the dominant isoform catalyzing S1P synthesis in the brain (Blondeau et al., 2007; Lei et al., 2017). SK2 protects against ischemic brain damage in stroke models (Pfeilschifter et al., 2011) and maintains hippocampal plasticity through S1P-mediated inhibition of histone deacetylases (Hait et al., 2014).

We previously reported that both S1P and SK2 activity decline with increasing Alzheimer's disease (AD) pathology in the human hippocampus and temporal cortex (Couttas et al., 2014). S1P loss was statistically significant at Braak stages III-IV, corresponding to a pre-AD neuropathological state (Braak and Braak, 1995). He et al. (2010) showed loss of S1P in AD frontal cortex, whereas another study showed reduced cytosolic and increased nuclear SK2 in AD (Dominguez et al., 2018). We have also shown an inverse correlation between S1P levels and age in the hippocampus of cognitively normal females (Couttas et al., 2018), suggesting that loss of neuroprotective S1P may sensitize to neurodegeneration.

Familial (inherited) AD manifests from middle age, whereas the sporadic form, which accounts for $>95 \%$ of cases, usually manifests after age 60 (Alzheimer's Association, 2019). Both forms are characterized by hippocampal atrophy, neurofibrillary tangle (NFT) pathology, and amyloid $\beta$ (A $\beta$ ) plaques (Holtzman et al., 2011; Alzheimer's Association, 2019). Familial AD is caused by mutations in the amyloid precursor protein (APP) and presenilin proteases that promote $\mathrm{A} \beta$ peptide formation (Holtzman et al., 2011). An APP gene variant that impairs $A \beta$ generation and protects against $\mathrm{AD}$ has also been identified (Jonsson et al., 2012), strongly implicating $\mathrm{A} \beta$ generation from APP in AD pathogenesis. However, cognitively normal individuals often present with high A $\beta$ burden (Price et al., 2009; Chételat et al., 2013), and therapies that clear cerebral $A \beta$ or inhibit $A \beta$ formation have repeatedly failed in clinical trials (Graham et al., 2017), implying that $\mathrm{A} \beta$ alone is not sufficient to precipitate $\mathrm{AD}$. One possibility is that age-related loss of neuroprotective factors such as S1P unmasks $A \beta$ neurotoxicity, triggering neurodegeneration.

Despite the neurotrophic properties of S1P, a previous study showed that SK2 and S1P are required for processing of APP to $\mathrm{A} \beta$ in cultured neurons (Takasugi et al., 2011). $A \beta$ secretion was significantly reduced following treatment of cells with sphingosine kinase inhibitors or siRNA to SK2, attributed to a requirement for SK2-generated S1P as a cofactor for APP cleavage by Bacel ( $\beta$-secretase). Bace1-mediated APP cleavage is the first of two proteolytic steps that result in $\mathrm{A} \beta$ peptide formation (Holtz-

\footnotetext{
Grant 1132524 (L.I.), NHMRC principal research fellowship 1136241 (L.I.), NHMRC-Australian Research Council (ARC) dementia fellowship 1110400 (T.A.C.), NHMRC dementia research team initiative 1095215 (T.K.), ARC discovery project Grants DP170100781 (L.I.) and DP170100843 (L.I., A.I.), and an Australian Research Training Stipend (M.L.). We thank the Sydney Mass Spectrometry core facility for subsidized access, the Western Sydney University animal caretakers, and the scientific and technical assistance of the Australian Centre for Microscopy \& Microanalysis at the University of Sydney.

The authors declare no competing financial interests.

${ }^{*} M$.L. and J.D.T. contributed equally to this work.

Correspondence should be addressed to Anthony Don at anthony.don@sydney.edu.au

https://doi.org/10.1523/JNEUROSCI.0524-19.2019

Copyright $\odot 2019$ the authors
}

man et al., 2011). It remains to be determined whether SK2 is a physiologically significant regulator of APP processing to A $\beta$ in vivo.

To resolve whether loss of SK2 and S1P sensitizes to neurodegeneration mediated by $A \beta$, and whether endogenous SK2 is required for $\mathrm{A} \beta$ formation from APP in vivo, we crossed SK2 knock-out (SK2 $\Delta$ ) mice to the J20 model, which expresses human APP with Swedish (K670N/M671L) and Indiana (V717F) familial AD mutations ( $\mathrm{APP}_{\text {SwInd }}$; Mucke et al., 2000; Palop et al., 2007). Deletion of SK 2 in J20 mice greatly reduced $A \beta$ deposition and $\mathrm{A} \beta$-dependent hippocampal epileptiform activity; but produced marked loss of hippocampal volume, myelin and oligodendrocytes, and created recognition memory deficits. These results demonstrate how $\mathrm{A} \beta$ may synergize with loss of neurotrophic lipid signaling in the aging brain to produce neurodegeneration.

\section{Materials and Methods}

\section{Transgenic mice}

SK2 $\Delta$ (Mizugishi et al., 2005) and J20 (PDGFB-APP ${ }_{\text {SwInd }}$ ) transgenic mouse lines (Mucke et al., 2000) were described previously. The $\mathrm{APP}_{\text {SwInd }}$ transgene was maintained heterozygous. SK2 ${ }^{\Delta / \Delta}$ mice were crossed to J20, generating J20.SK2 ${ }^{+/ \Delta}$ breeders that were used to create $\mathrm{J} 20 . \mathrm{SK} 2^{\Delta / \Delta}$ and J20.SK2 ${ }^{+++}$. These were crossed to SK2 ${ }^{+/+}$or SK2 ${ }^{\Delta / \Delta}$ siblings derived from a SK2 ${ }^{+/ \Delta} \times \mathrm{SK} 2^{+/ \Delta}$ cross, to ensure that all four genotypes (SK2 ${ }^{+/+}, \mathrm{SK} 2^{\Delta / \Delta}, \mathrm{J} 20 . \mathrm{SK} 2^{+/+}, \mathrm{J} 20 . \mathrm{SK} 2^{\Delta / \Delta}$ ) were on the same C57BL/6J genetic background.

Male mice were used for these experiments. Mice were grouped housed and kept under a $12 \mathrm{~h}$ light/dark schedule, with food and water provided ad libitum. Crinkle nest and tissues were provided for enrichment. Mice were 8 or 13 months of age at cull. Experiments were performed in accordance with the Australian Code of Practice for the Care and Use of Animals for Scientific Purposes and were approved by the Western Sydney University Animal Care and Ethics Committee (A11866). Electroencephalography (EEG) recording on live mice was performed under University of New South Wales (UNSW) Sydney animal care and ethics committee approval 16/48A.

S1P, sphingosine, and SK2 activity were also quantified using cortical tissue from 6 -month-old male ( $n=6$ per genotype) and female $(n=2$ per genotype) C57BL/6J mice heterozygous for the tau (K369I) transgene, and WT littermates (L. M. Ittner et al., 2008; UNSW Sydney animal care and ethics committee approval 16/22A).

\section{Cognitive tests}

Male mice were tested at 7 and 12 months of age. All tests were conducted during the first $5 \mathrm{~h}$ of the light phase to minimize the effects of circadian rhythm on performance. Mice were first subjected to a basic physical examination battery that included the wire-hang test, pole test, visual cliff test, rotarod, grip strength test, and ring test. All genotypes showed no phenotype in these physical ability tests. This was followed by the open field, novel object recognition, social preference and social novelty, cheeseboard paradigm, and Y-maze tests (only the 12 month cohort were tested in Y-maze). The inter-test interval was $48 \mathrm{~h}$, and the experimenter remained blinded to genotype during testing and data analysis. Data from the cheeseboard paradigm is not presented, as the data were highly variable and the WT mice as a group (as well as the other genotypes) failed to spend $>12.5 \%$ of their time exploring the eighth of the board containing the reward in the probe trial.

Y-maze. A three-armed Y-maze was surrounded by external cues that provide references for spatial memory (tripod, large geometric shapes on the walls and curtain). Mice were placed in the start arm with one arm (novel arm) closed off, and allowed to explore the start and familiar arm for $10 \mathrm{~min}$. After a $30 \mathrm{~min}$ interval, test mice were placed back into the maze with the novel arm open, and allowed to explore for $10 \mathrm{~min}$. The start, novel and familiar arms were quasi-randomized for each animal. Entries into, time spent, and distance traveled in each arm of the maze was recorded and analyzed using ANY-maze software (Stoelting). The number of entries and distance traveled in the novel arm were expressed as a percentage of the total for all three arms, and a one-sample (two- 
tailed) $t$ test was used to determine whether this percentage differed from the that expected by chance (33.33\%) for each genotype.

Social preference and social novelty test. The social preference test (SPT) and social novelty test (SNT) assess the innate tendency of a test mouse to explore a novel mouse (Cheng et al., 2013). The apparatus consists of three clear Plexiglas chambers separated by rectangular passageways (Cheng et al., 2013). The test mouse was isolated for $30 \mathrm{~min}$ before testing, and then subjected to a habituation trial in which the mouse was placed in the central chamber and allowed to explore the apparatus for 5 $\mathrm{min}$. In the SPT, a cylindrical cage enclosing a male, unfamiliar, weightmatched A/JArc mouse (Animal Resources Centre, Western Australia, Australia) was placed on one end of the outer chamber and an empty cage in the opposite outer chamber in a quasi-randomized manner. The test mouse was again placed into the central chamber to freely explore the apparatus for $10 \mathrm{~min}$. In the SNT, the familiar mouse encountered in the SPT and a novel male A/JArc were positioned at polar ends of the apparatus' outer chambers. The test mouse was placed in the central chamber and allowed to explore for $10 \mathrm{~min}$. There was a $20 \mathrm{~min}$ intertrial interval and bedding was changed between trials. ANY-maze software was used to quantify the time spent in chambers and time spent nosing the enclosures (position of the nose is $\leq 1 \mathrm{~cm}$ from the chamber). For statistical analysis, the time spent nosing the inhabited cage (SPT), and time spent nosing the cage with the novel, unfamiliar mouse (SNT) was expressed as a percentage of time spent nosing both cages. This percentage was compared with that expected by chance $(50 \%)$ in a one-sample $t$ test for each genotype.

Novel object recognition test. The novel object recognition test (NORT) evaluates the rodent's innate preference of investigating a novel over a familiar object (Karl et al., 2012). The task consists of three trials: habituation, training, and test trials. The apparatus is made of gray Perspex $(35 \times 35 \times 30 \mathrm{~cm})$. During habituation, two identical objects were placed in opposite corners of the chamber and the test mouse was put into the chamber for $10 \mathrm{~min}, 24 \mathrm{~h}$ before training and test trials. On the following day, the test mouse was placed back into the center of the same chamber with a new set of identical objects and allowed to explore for 10 min (training). After a $30 \mathrm{~min}$ interval, the test phase was initiated by replacing one of the familiar, identical objects with a novel object. The mouse was again placed in the center of the chamber and allowed to explore the objects for another $10 \mathrm{~min}$. ANY-maze software was used to quantify time spent nosing the objects (position of the nose is $\leq 1 \mathrm{~cm}$ from an object). The objects used were LEGO Duplo farm animals, which were cleaned thoroughly with $80 \%$ (v/v) ethanol between tests. Statistical significance was determined as described above for SPT/SNT.

\section{Electroencephalography}

EEG was performed on 13-month-old male mice. Wire EEG electrodes on remote telemetric transmitters (DSI) were implanted, and data were recorded exactly as described previously (A. Ittner et al., 2014). Recordings were screened manually for movement artifacts and only artifactfree EEG passages were used in analysis. Raw local field potentials were noise filtered using a powerline noise filter (Neuroscore, DSI). Analysis of EEG recordings was performed using the NeuroScore software v3.0 (DSI) with integrated spike detection module, as described previously (A. Ittner et al., 2014). Spectral analysis of intra-ictal sequences was performed using the integrated fast Fourier transform spectral analysis function of NeuroScore. Frequency bands of $\theta$ and $\gamma$ wave forms were defined between 4 and $12 \mathrm{~Hz}$ and 25-100 Hz, respectively, with further distinction of low $\gamma$ oscillations at $25-40 \mathrm{~Hz}$ and high $\gamma$ oscillations at $40-100$ Hz. $\theta$ and $\gamma$ spectral contributions were quantified by area-under-curve (AUC) analysis across the defined frequency band in at least three artifact- and hypersynchronous spike-free sequences per recording (each $1 \mathrm{~min}$ in length). Cross-frequency coupling of $\theta$ phase and $\gamma$ amplitude (Tort et al., 2010) was performed using MATLAB, as described previously (A. Ittner et al., 2014). Phase-amplitude distributions and modulation indices were determined from at least three artifact- and hypersynchronous spike-free sequences (each $30 \mathrm{~s}$ ) per recording.

\section{Lipidomic analysis by liquid chromatography-tandem} mass spectrometry

Lipids were extracted from $\sim 20 \mathrm{mg}$ mouse brain tissue using a two-phase methyl-tert-butyl ether-methanol-water (10:3:2.5 v/v/v) extraction solvent procedure (Matyash et al., 2008). Internal standards ( $2 \mathrm{nmol}$ each of d18:1/17:0 ceramide, d18:1/12:0 sphingomyelin, d18:1/12:0 hexosylceramide, and d18:1/12:0 sulfatide; and 250 pmol of d17:1 sphingosine and $\mathrm{d} 17: 1 \mathrm{~S} 1 \mathrm{P})$ were added at the start of the extraction procedure. Lipids were detected in positive ion mode, using multiple-reaction monitoring on a TSQ Altis mass spectrometer equipped with Vantage HPLC (ThermoFisher Scientific). Lipid peaks were identified using both precursor ion mass and diagnostic product ions $(\mathrm{m} / \mathrm{z} 264.3$ for all sphingosinebased lipids including S1P; $m / z 250.2$ for 17:1 sphingosine and S1P internal standards; both $\mathrm{m} / \mathrm{z} 184.1$ and $\mathrm{m} / \mathrm{z} 264.3$ for sphingomyelin). Sphingosine, S1P, sphingomyelin, hexosylceramide, and sulfatide were resolved using a previously-described binary gradient (Wong et al., 2012) with some modifications. A $2.1 \times 100 \mathrm{~mm}$ C8 column was used $(1.8 \mu \mathrm{M}$ particle size; Agilent), with flow rate $0.3 \mathrm{ml} / \mathrm{min}$. Mobile phase A was $0.2 \%$ formic acid, $2 \mathrm{~mm}$ ammonium formate in water; and B was $1 \%$ formic acid, $2 \mathrm{~mm}$ ammonium formate in methanol. Total run time was $24 \mathrm{~min}$, starting at $80 \% \mathrm{~B}$ and holding for $2 \mathrm{~min}$, increasing to $100 \% \mathrm{~B}$ from 2 to $14 \mathrm{~min}$, holding at $100 \%$ until $20.5 \mathrm{~min}$, then returning to $80 \%$ $\mathrm{B}$ at $21 \mathrm{~min}$, and holding at $80 \% \mathrm{~B}$ for a further $3 \mathrm{~min}$. Ceramides were resolved on a $2.1 \times 150 \mathrm{~mm}$ Poroshell 120 HILIC-Z column $(2.7 \mu \mathrm{M}$ particle size; Agilent). An isocratic mobile phase comprising $97 \%$ acetonitrile, $2 \%$ methanol, $1 \%$ formic acid, and $2 \mathrm{~mm}$ ammonium formate was used, with run time $9 \mathrm{~min}$ and flow rate $0.2 \mathrm{ml} / \mathrm{min}$. Liquid chromatography peaks were integrated using TraceFinder 4.1 software (ThermoFisher Scientific), and expressed as ratios to the class-specific internal standard. Absolute values were determined from external standard curves for each lipid class.

\section{Amyloid $\beta$ ELISA}

Brain homogenates were prepared by homogenizing hippocampal $(\sim 25$ $\mathrm{mg})$ tissue in 10 volumes $(250 \mu \mathrm{l})$ of TBS extraction buffer $(140 \mathrm{~mm}$ $\mathrm{NaCl}, 3 \mathrm{~mm} \mathrm{KCl}, 25 \mathrm{~mm}$ Tris, $\mathrm{pH}$ 7.4, $5 \mathrm{~mm}$ EDTA, 1, $2 \mathrm{~mm} \mathrm{10-}$ phenanthroline, $1 \%$ Igepal CA 630, complete EDTA-free protease inhibitor) using a Biospec mini beat beater homogenizer with 425-600 $\mu \mathrm{m}$ acid-washed glass beads (Sigma-Aldrich). Homogenates were centrifuged at $16,100 \times g$ for $30 \mathrm{~min}$ at $4^{\circ} \mathrm{C}$, and the supernatant was collected as the soluble fraction. The pellet was then re-homogenized in $10 \mathrm{vol}-$ umes $(250 \mu \mathrm{l})$ of guanidine $\mathrm{HCl}$ buffer $(4.7 \mathrm{M}$ guanidine $\mathrm{HCl}, 12.5 \mathrm{~mm}$ Tris, $\mathrm{pH}$ 8.0) with bead beating. Homogenates were incubated on a rotating wheel at $4^{\circ} \mathrm{C}$ for $16 \mathrm{~h}$. Samples were centrifuged at $16,1000 \times g$ for $30 \mathrm{~min}$ at $4^{\circ} \mathrm{C}$ and the supernatant was collected as the insoluble $\mathrm{A} \beta$ fraction. Protein concentrations determined using the bicinchoninic acid (BCA) assay (ThermoFisher Scientific). ELISA kits from ThermoFisher Scientific were used to quantify $\mathrm{A} \beta 40$ (KHB3481) and $\mathrm{A} \beta 42$ (KHB3441).

\section{Immunohistochemistry and volumetric analysis}

Mice were perfused transcardially using sterile saline, brains were removed, divided sagittally, and postfixed overnight with $4 \%$ paraformaldehyde in PBS. Tissue was transferred to $30 \%$ sucrose cryoprotectant and stored at $4^{\circ} \mathrm{C}$. Half brains were sectioned at $40 \mu \mathrm{m}$ using a ThermoFisher Scientific Cyrotome FSE Cryostat and stored at $-30^{\circ} \mathrm{C}$ in cryoprotectant consisting of $25 \%$ glycerol, $25 \%$ ethylene glycol in PBS. For immunofluorescence, sections were washed with PBS containing $0.1 \%$ Tween 20 between each step. Antigen retrieval was performed in $10 \mathrm{~mm}$ sodium citrate, $\mathrm{pH} 6.0$, with $0.01 \%$ Tween 20 , heated to $70^{\circ} \mathrm{C}$ for $10 \mathrm{~min}$. Sections were incubated in blocking solution (5\% goat serum, $0.1 \%$ BSA, $0.1 \%$ Triton X-100 in PBS) for $1 \mathrm{~h}$, then overnight at $4^{\circ} \mathrm{C}$ in primary antibodies diluted in blocking solution. Primary antibodies were as follows: anti-A $\beta$ clone 6E10 (BioLegend, 803001; 1:500 dilution), anti-Olig2 (Abcam, Ab109186; 1:1000 dilution), anti-NeuN (Merck, MAB377; 1:500 dilution), anti-MBP (Abcam, Ab40390; 1:500 dilution), anti-neurofilament-H (Abcam, Ab4680; $1: 10^{4}$ dilution), and rabbit anti-ASPA (gift from Matthias Klugmann, UNSW Sydney). To visualize the primary antibody, sections were incubated for $2 \mathrm{~h}$ with AlexaFluor 488-, 546-, 633-, or 647-conjugated 
secondary antibodies (1:500 in blocking solution). Thioflavin S (SigmaAldrich, T1892) staining was performed last, incubating slides for $8 \mathrm{~min}$ at RT in $0.002 \%$ thioflavin S solution, followed by two washes with $50 \%$ EtOH in TBS. Sections were mounted using ProLong Gold anti-fade with DAPI (Life Technologies, P36935). Slides were imaged using an Olympus Virtual Slide microscope VS1200 or Nikon C2 confocal microscope.

In all cases, the experimenter remained blinded to the treatment groups until after quantification.

Quantification of $A \beta$ plaques. Hippocampal plaque number and burden (percentage of plaque area relative to total area of the hippocampus) was quantified in four sections per mouse. The mean for each mouse was graphed and used for statistical analysis. Plaque number and burden were quantified only from plaques double-labeled with 6E10 and thioflavin S, using the binary feature extractor of the BioVoxxel plugin in ImageJ. Immunofluorescence micrographs of $6 \mathrm{E} 10$ were used as the selector image for the corresponding thioflavin S (object) images to determine the overlap of both stains within the hippocampus.

Estimation of hippocampal volume. Six equidistant sagittal sections from each animal, $\sim 0.36-2.28 \mathrm{~mm}$ from the midline, were stained with mouse anti-NeuN and rabbit anti-Olig2. Hippocampal cross-sectional area on each section was measured using ImageJ and multiplied by 320 $\mu \mathrm{m}$ to account for the distance between sections. The mean area for each mouse was graphed and used for statistical analysis. In some cases, only four or five sections were obtained for each mouse (because of reduced hippocampal size). The area covered by NeuN-positive signal (as a proportion of total hippocampal area) was determined using ImageJ.

Quantification of Olig2-positive cells. Counting of Olig2-positive cells used the same sections as were used for estimation of hippocampal volume and area. Images were first processed using the automatic contrast enhancement function, then analyzed for particles based on size $(>10$ $\left.\mu \mathrm{m}^{2}\right)$ and circularity $(0.25-1.0)$ in ImageJ. To account for variability in staining intensity between different staining batches (7- and 13-monthold mice), sections from WT animals were used as inter-batch staining controls.

\section{Cell culture}

The MO3.13 oligodendrocyte cell line was obtained from N. Cashman (University of Toronto), and cultured in DMEM medium supplemented with $10 \%$ fetal bovine serum (FBS) and $2 \mathrm{~mm} \mathrm{~L}$-glutamine. The Oli-neu oligodendrocyte cell line was obtained from Eva-Maria Kramer-Albers (Johannes Gutenberg-Universitat, Mainz, Germany). They were cultured in Sato medium supplemented with $2 \mathrm{~mm}$ L-glutamine and 1\% horse serum, on plates coated with $0.01 \%$ poly-D-lysine, as described previously (Jung et al., 1995). SH-SY5Y neuroblastoma cells were obtained from Paul Witting (University of Sydney), and cultured in RPMI medium supplemented with 10\% FBS and 2 mM L-glutamine. U251 cells were from American Type Culture Collection, and cultured in DMEM with 10\% FBS and 2 mm L-glutamine. Primary human embryonic astrocytes were isolated from the Human Fetal Tissue Biobank at Macquarie University Hospital, under ethics approval \#5201600719 (Guillemin et al., 2005), and cultured in RPMI medium with 10\% FBS and $2 \mathrm{~mm}$ L-glutamine. Experiments with primary human astrocytes were approved by the University of Sydney human ethics committee (\#2017/270).

Cell culture media, L-glutamine, and FBS were purchased from Life Technologies. Poly-D-lysine and reagents for Sato medium were purchased from Sigma-Aldrich.

Cells were treated for the indicated times with $3 \mu \mathrm{g} / \mathrm{ml} \mathrm{U18666A}$ (Cayman Chemical; Lu et al., 2015), $5 \mathrm{mM} \mathrm{NH}_{4} \mathrm{Cl}$, or $100 \mu \mathrm{M}$ leupeptin (Cayman Chemical), then extracted into RIPA buffer (20 mM Tris- $\mathrm{HCl}, \mathrm{pH}$ 7.4, $100 \mathrm{~mm} \mathrm{NaCl}, 1 \mathrm{~mm}$ EDTA, 0.1\% SDS, 0.5\% sodium deoxycholate, $1 \%$ Triton X-100, 10\% glycerol, $1 \mathrm{~mm} \mathrm{NaF}, 2 \mathrm{mM} \mathrm{Na}_{4} \mathrm{P}_{2} \mathrm{O}_{7}$, complete EDTA-free protease inhibitor cocktail; Sigma-Aldrich). Protein concentration was determined with the BCA assay. One-half of the RIPA lysate was used for Western blotting, and the other half for S1P and sphingosine quantification. S1P and sphingosine internal standards (d17:1, $250 \mathrm{nmol}$ each) were added before extraction, and endogenous S1P and sphingosine were quantified as described previously (Couttas et al., 2014).

\section{SK2 activity assay}

SK2 activity was assayed as described previously (Couttas et al., 2014). Cells or tissue samples were extracted with sonication in $20 \mathrm{mM}$ HEPES, $\mathrm{pH}$ 7.4, $10 \mathrm{~mm} \mathrm{KCl}, 1 \mathrm{~mm}$ dithiothreitol (DTT), $3 \mathrm{~mm} \beta$-glycerophosphate, 5 $\mathrm{mm} \mathrm{NaF}, 2 \mathrm{~mm}$ sodium orthovanadate, and complete protease inhibitor cocktail. Reactions were run for $30 \mathrm{~min}$ at $37^{\circ} \mathrm{C}$, using $\mathrm{d} 17: 1$ sphingosine $(10 \mu \mathrm{M})$ as the substrate and $5 \mu \mathrm{g}$ of protein, and stopped with the addition of 4 volumes of methanol. Reaction buffer was 25 mM HEPES, pH 7.4, $500 \mathrm{~mm} \mathrm{KCl,} 2.5 \mathrm{~mm} \mathrm{MgCl}_{2}, 2 \mathrm{~mm}$ ATP, 2 mm sodium orthovanadate, $5 \mathrm{~mm} \mathrm{NaF}, 1 \mathrm{~mm}$ 4-deoxypyridoxine, and $10 \mu \mathrm{M}$ fumonisin $\mathrm{B}_{1}$ (Cayman Chemical). Reagents were from Sigma-Aldrich unless otherwise specified. S1P (d17:1) product formed in the reactions was quantified using liquid chromatography-tandem mass spectrometry with d18:0 S1P used as the internal standard.

\section{Western blotting}

Tissue samples $(\sim 20 \mathrm{mg})$ were homogenized in $0.2 \mathrm{ml}$ homogenization buffer (20 mм HEPES, pH 7.4, 10 mм KCl, 1 mм DTT, 3 mм $\beta$-glycerophosphate, $5 \mathrm{~mm} \mathrm{NaF}, 2 \mathrm{~mm}$ sodium orthovanadate, and complete protease inhibitor cocktail; Roche) using a Biospec mini bead beater with acid-washed glass beads $(425-600 \mu \mathrm{m})$. The supernatant was transferred to a new tube and the beads washed with another $0.2 \mathrm{ml}$ buffer, which was then combined with the first extract. Extracts were centrifuged at $1000 \times$ $g$ for $10 \mathrm{~min}$ to clear debris, and the supernatant was transferred to new tubes. Protein concentration was determined with the BCA assay (ThermoFisher Scientific). Protein lysates $(15 \mu \mathrm{g})$ were resolved on $4-12 \%$ NU-PAGE gels (ThermoFisher Scientific), transferred to polyvinylidene difluoride membrane, and immunoblotted with mouse anti-APP (6E10; 1:1000 dilution), rabbit anti-MBP (Abcam, catalog \#ab40390; 1:1000 dilution), mouse anti-PLP (clone aa3; 1:200 dilution; gift from EvaMaria Albers, University of Mainz), rabbit anti-MOG (Abcam, catalog \#ab32760; 1:1000 dilution), mouse anti- $\beta$ III-tubulin (BioLegend, cata$\log$ \#TUBB3; 1:1000 dilution), chicken anti-neurofilament $\mathrm{H}$ (Abcam, catalog \#ab4680; 1:10 ${ }^{6}$ dilution), and rabbit anti-LC3B (Cell Signaling Technology, clone D11, catalog \#3868; 1:1000 dilution). Signal was developed using Immobilon Western chemiluminescent HRP substrate (Merck). Membranes were stripped using stripping buffer (15 g/L glycine, $0.1 \%$ SDS, $1 \%$ Tween $20, \mathrm{pH} 2.2$ ), and re-probed with rabbit anti$\beta$-actin (Abcam, catalog \#ab8227; 1:5000 dilution) as a loading control. Densitometry was performed using Bio-Rad Image Lab software.

\section{Experimental design and statistical analyses}

The project was designed to test the effect of SK2 deletion on neurodegeneration and memory deficits in the J20 mouse model at two different ages of the mice: the first being before substantial $\mathrm{A} \beta$ plaque deposition (7-8 months), and the second at a time when all J20 mice were expected to show some $\mathrm{A} \beta$ deposition but still early enough to detect potential differences in pathology or behavior between $\mathrm{J} 20$ (i.e., SK2 ${ }^{+/+}$) and J20.SK2 $\Delta$ (i.e., SK2 ${ }^{-1-}$ ) mice (12-13 months). A sample size of 12 mice per group was chosen for memory tests based on prior studies with $\mathrm{AD}$ mouse models (Karl et al., 2012; Cheng et al., 2013). These were divided into sample sizes of six for immunofluorescence and biochemical analyses. The number of sections analyzed for each immunofluorescence measure is reported in the Immunohistchemistry and volumetric analysis section.

All statistical analysis was performed using GraphPad Prism. Ordinary one-way ANOVA was used to test the effect of genotype or cell treatments in single variable measures. In most analyses, Sidak's post-test was used to perform four comparisons: WT-SK2 $\Delta$, WT-J20, WT-J20.SK2 $\Delta$, and J20-J20.SK2 $\Delta$. For lipidomic data, ANOVA $p$ values for individual lipids were adjusted for multiple comparisons using the false discovery rate approach of Benjamini, Krieger, and Yekutieli (threshold: $Q=5 \%$ ), after which only sphingosine and S1P remained significant. Dunnett's posttest was applied to compare levels of individual lipids to the WT control group when a significant result $(p<0.05)$ was detected with one-way ANOVA. Ordinary two-way ANOVA was used when a second variable was involved (see Figs. 3C,J, $7 E$ ), with Dunnett's post-test to compare each genotype to the WT control.

To test for statistical significance in memory tests, the performance of subjects in each genotype group was compared with that expected by 
Table 1. SK2 deletion affects hippocampal S1P and sphingosine content

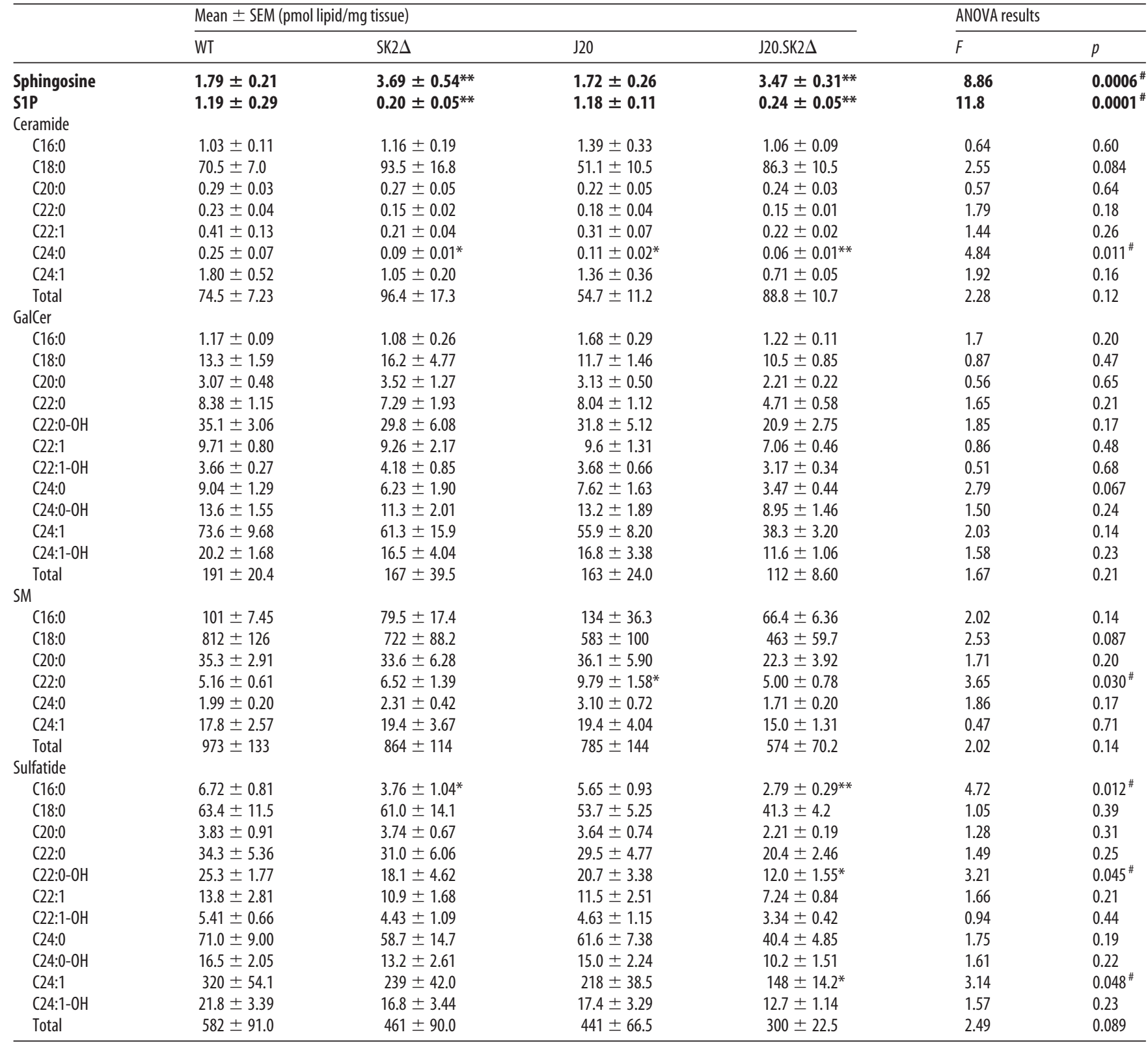

Levels of S1P, sphingosine, and other sphingolipids in the hippocampus of WT, SK2 $\Delta, J 20$, and J20.SK2 $\Delta$ mice at 8 months of age. All lipids shown have the common 18:1 sphingosine base. Fand $p$ values for one-way ANOVA are indicated; $\# p<0.05$. After adjusting ANOVA $p$ values for multiple comparisons, sphingosine and S1P were significant at $Q<0.05$, indicated by bold font. Dunnett's post-test was used to compare group means to the WT for individual lipids significant at $p<0.05$ in univariate ANOVA. ${ }^{*} p<0.05,{ }^{* *} p<0.01$.

chance (either 33.3 or $50 \%$ ) using one-sample $t$ tests. This method most effectively tests each genotype for a specific preference for the novel arm (Y-maze), novel mouse (SNT), or novel object (NORT). Unpaired, twotailed $t$ tests were used to compare A $\beta$ content between J20 and J20.SK2 $\Delta$ mice. All data are available to interested researchers upon reasonable request.

\section{Results}

SK2 deletion alleviates $\mathrm{A} \boldsymbol{\beta}$ burden

To determine the effect of SK2 deficiency on A $\beta$ plaque formation and associated neuropathology, SK2 $\Delta$ were crossed to J20 mice, generating J20.SK2 $\Delta$ mice. We first determined the effect of SK2 deletion and the $\mathrm{APP}_{\text {SwInd }}$ transgene on levels of S1P, sphingosine, and other sphingolipids in the hippocampus at 8 months of age (Table 1). After adjusting for multiple comparisons, only sphingosine and S1P were significantly affected by genotype. Mean cortical S1P levels were 83\% lower in SK2 $\Delta$ compared with
WT mice, whereas the SK2 substrate sphingosine was twofold higher, in agreement with previous results (Lei et al., 2017). S1P and sphingosine content was not affected by the $\mathrm{APP}_{\text {SwInd }}$ transgene (i.e., unchanged in J20 mice). Although not statistically significant, a trend reduction in the major myelin lipid constituents galactosylceramide, sulfatide, and sphingomyelin was apparent in the J20.SK $2 \Delta$ line.

Significant $\mathrm{A} \beta$ plaque pathology was observed in 13-monthold but not 8 -month-old J20 mice (Fig. $1 A$ ). Mean A $\beta$ plaque number and hippocampal plaque burden were $56 \%(p=0.033$ by $t$ test) and 75\% ( $p=0.003)$ lower, respectively, in J20.SK2 $\Delta$ compared with $\mathrm{J} 20$ (Fig. $1 B, C$ ). No plaques were detected in $\mathrm{WT}$ or SK2 $\Delta$ mice, which do not express the human $\mathrm{APP}_{\text {SwInd }}$ transgene. In agreement with the immunofluorescence data, soluble and insoluble $A \beta 40$ and $A \beta 42$ peptide levels, as determined by ELISA, were lower in J20.SK2 $\Delta$ compared with J20 mice (Fig. 

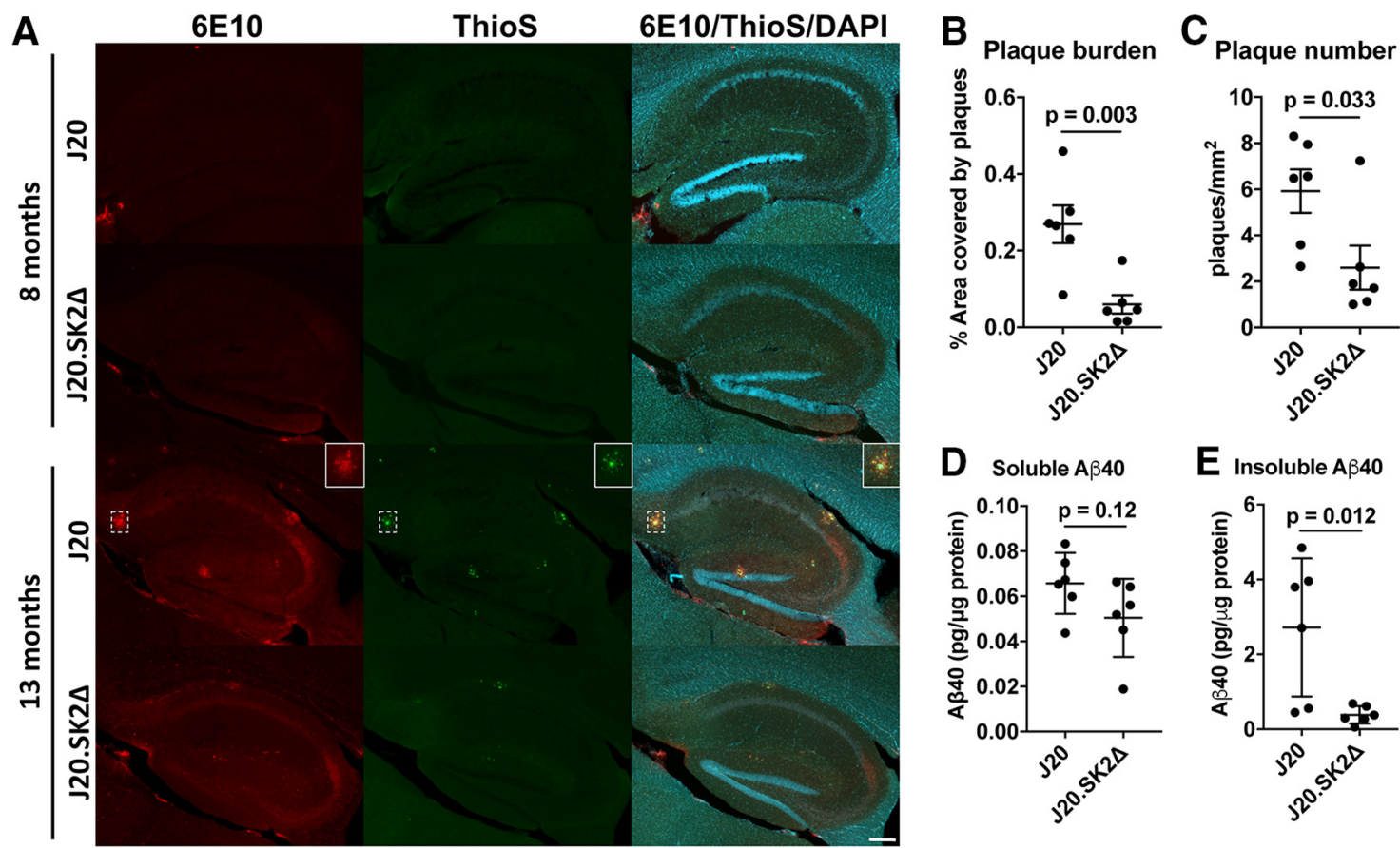

E Insoluble A 340
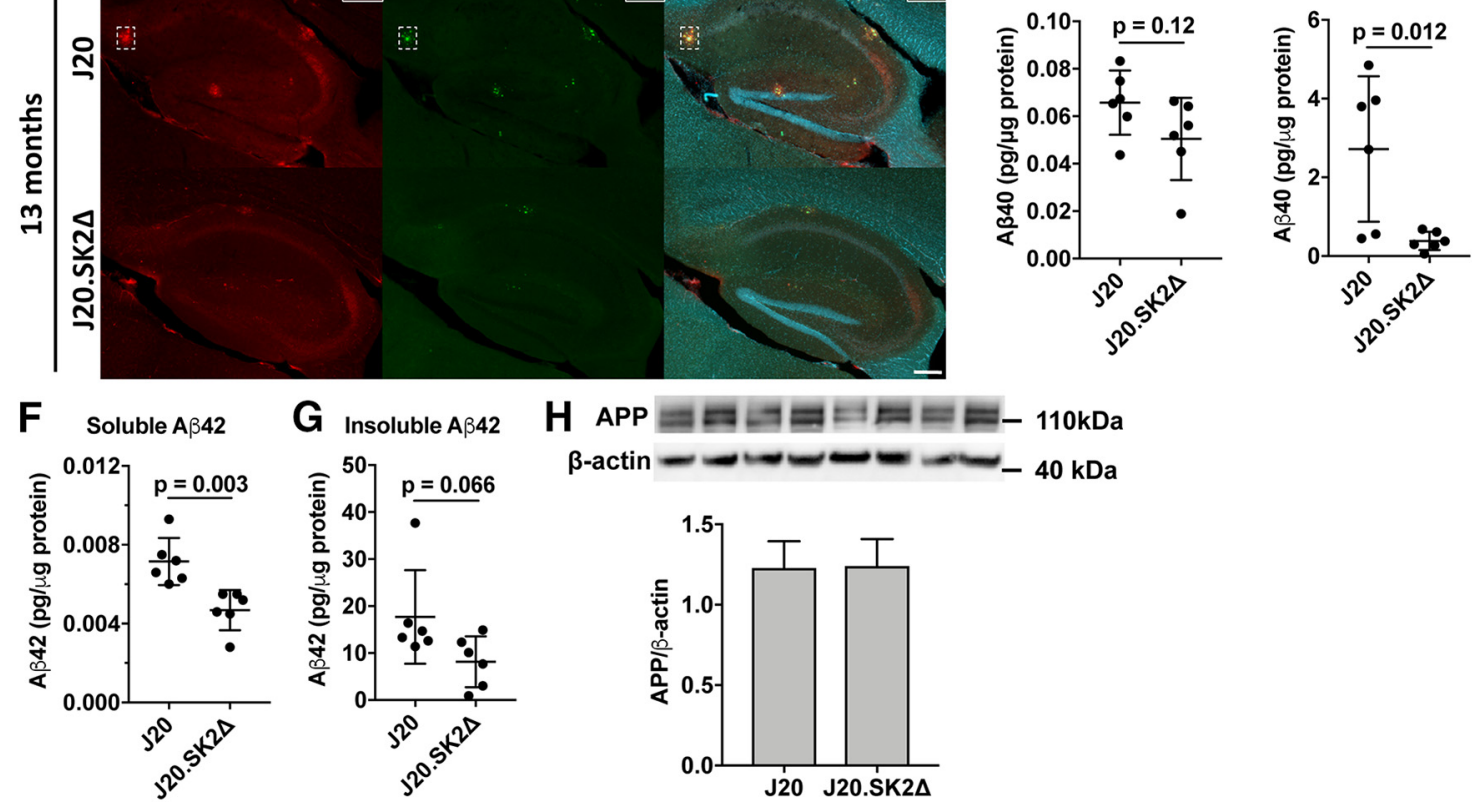

Figure 1. Loss of SK2 greatly reduces $A \beta$ production. $A$, Immunofluorescence colabeling with $6 E 10$ antibody (red), thioflavin $S$ (ThioS; green), and DAPI (blue) in hippocampus of J20 and J20.SK2 $\Delta$ mice at 8 and 13 months of age. Box (closed border) shows an enlarged view of an $A \beta$ plaque (dashed box). Scale bar, $200 \mu$ m. $B, A \beta$ plaque burden (percentage hippocampal area covered by plaques) and (C) A $\beta$ plaque number in 13-month-old mice. $\boldsymbol{D}, \boldsymbol{E}, A \beta 40$ and $(\boldsymbol{F}, \boldsymbol{G}) \mathrm{A} \beta 42$ levels in hippocampus of 13-month-old J20.SK2 $\Delta$ or J20 mice, as determined by ELISA. A $\beta$ levels were below the limit of detection in WT or SK2 $\Delta$ mice. $\boldsymbol{H}$, Western blot for full-length APP in J20 and J20.SK2 $\Delta$ mice. Statistical significance in $\boldsymbol{B}-\boldsymbol{H}$ was determined by two-tailed, unpaired $t$ tests ( 6 mice per group).

$1 D-G)$. Mean total $\mathrm{A} \beta$ content $(\mathrm{A} \beta 40+\mathrm{A} \beta 42)$ was $58 \%$ lower $(p=0.044$ by $t$ test $)$ in J20.SK2 $\Delta$ mice. $\mathrm{APP}_{\text {SwInd }}$ transgene expression was equivalent between J20 and J20.SK2 $\Delta$, indicating that reduced $\mathrm{A} \beta$ could not be attributed to altered transgene expression (Fig. 1H).

SK2 deletion reduces $\mathrm{A} \boldsymbol{\beta}$-dependent epileptiform activity and neuronal network deficits

Mouse models of $\mathrm{A} \beta$ overproduction show neuronal network aberrations in the hippocampus that can be quantified with EEG, including spontaneous epileptiform activity, modulation of power spectrum densities, and impaired network connectivity assessed by cross-frequency coupling of $\gamma$ amplitude with $\theta$ phase (Palop et al., 2007; Verret et al., 2012; A. Ittner et al., 2014). EEG recording from the hippocampus showed epileptiform activity with frequent spontaneous hypersynchronous spikes in J20 mice, which was not present in WT or SK2 $\Delta$ mice ( $F=9.6, p=0.0016$ by one-way ANOVA; Fig. $2 A, B)$. The number of epileptiform events was markedly reduced in J20.SK $2 \Delta$ mice ( $69 \%$ reduction in spikes $/ \mathrm{min}, p=0.017$ by Sidak's post-test), consistent with their lower $A \beta$ burden.

To address contributions of different wave forms, we performed power spectral density analysis of inter-ictal sequences during the wake state (Buzsáki and Moser, 2013). Spectral distribution of oscillations was comparable between WT, SK2 $\Delta$, and J20 mice, whereas J20.SK2 $\Delta$ showed lower power across the entire oscillation spectrum $(p<0.0001$ compared with WT by Dunnett's post-test following two-way ANOVA; Fig. $3 C$ ). Theta oscillations $(4-12 \mathrm{~Hz})$, a key contribution of hippocampal EEG derived mainly from large pyramidal neurons (Buzsáki and Moser, 2013), were 59\% lower in J20.SK2 $\Delta$ compared with WT controls (Fig. $2 D, E$ ), although this was not statistically significant $(p=0.075)$. Spectral power of low $\gamma$ frequencies $(25-50 \mathrm{~Hz})$ was significantly regulated by genotype $(F=7.2, p=0.005$ by oneway ANOVA) and 53\% lower in J20.SK2 $\Delta$ compared with WT mice $(p=0.038$; Fig. $2 F, G)$.

Interactions between hippocampal $\theta$ and $\gamma$ oscillations in EEG recordings correlate in strength and dynamics with cognitive functions such as learning and memory (Tort et al., 2009). Cross-frequency coupling between $\theta$ phase and $\gamma$ amplitude is a proxy of this network modality (Tort et al., 2009; Goutagny et al., 2013). Cross-frequency coupling was reduced in J20 mice and restored in J20.SK2 $\Delta$ for frequency pairs between $\theta: 4-10 \mathrm{~Hz}$ and high $\gamma: 40-100 \mathrm{~Hz}$, as evident in comodulograms (Fig. $2 \mathrm{H}$ ) and the modulation index, a quantitative measure of cross-frequency cou- 

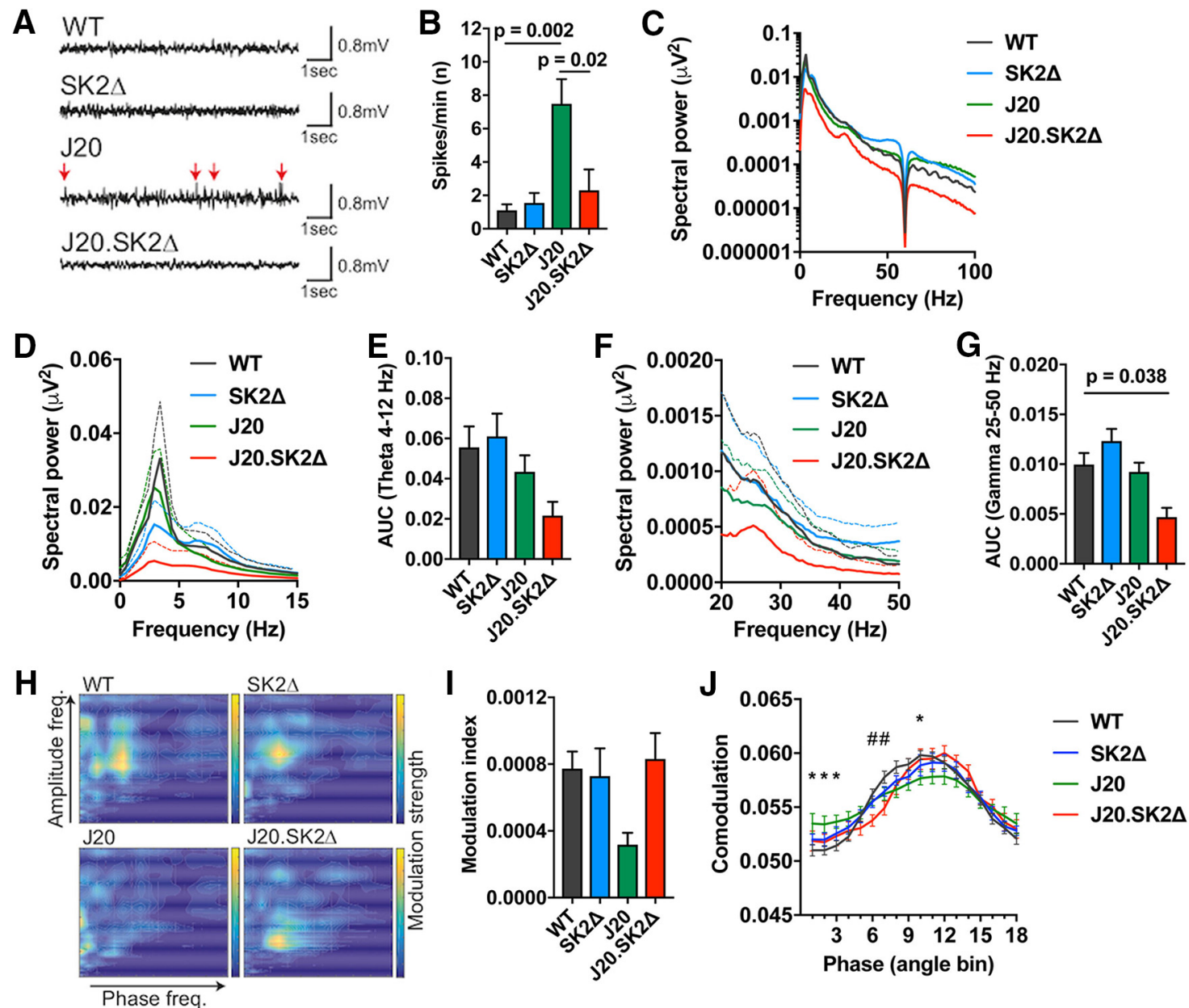

Figure 2. Deletion of SK2 abates hypersynchronous activity and cross-frequency coupling deficits in J20 mice. $\boldsymbol{A}$, Representative traces and ( $\boldsymbol{B}$ ) quantification of spontaneous hypersynchronous events (spikes/min), in hippocampal EEG recordings from 13-month-old mice. Arrows indicate spontaneous hypersynchronous events. Means \pm SEM shown; $n=3-5$ mice per group. $\boldsymbol{C}$, Spectral power density plot of hippocampal EEG recordings over the frequency range $0-100 \mathrm{~Hz}$. The signal at $60 \mathrm{~Hz}$ was eliminated by a power line filter. $\boldsymbol{D}, \boldsymbol{E}$, Spectral power density of $\theta$ oscillation $(4-12$ $\mathrm{Hz}$ ) and $(\boldsymbol{F}, \boldsymbol{G})$ low y oscillation ( $25-50 \mathrm{~Hz}$ ) in WT, SK2 $\Delta, J 20$, and J20.SK2 $\Delta$ mice. Mean (solid line) and SEM (dotted line) shown in $\boldsymbol{D}$ and $\boldsymbol{F}$; AUC shown in $\boldsymbol{E}$ and $\boldsymbol{G}$. $\boldsymbol{H}$, Representative c0-modulograms $(30 \mathrm{~s})$ of EEG recordings. Color contour indicates strength of co-modulation of amplitude by phase at individual frequency pairs. $I$, Modulation index of cross frequency coupling between $\theta$ phase and $\gamma$ frequencies in EEG recordings. Mean \pm SEM. Statistical significance in $\boldsymbol{B}, \boldsymbol{E}, \boldsymbol{G}$, and $(\boldsymbol{I})$ was determined by ANOVA with Sidak's post-test. $P$ values $<0.05$ are indicated on graphs. Data were derived from three to five mice per group. J, Phase-amplitude co-modulation across $\theta$ phase bins. Mean (solid line) and SEM shown; $n=3-5$. Statistical significance was determined by two-way ANOVA with Dunnett's post-test. * $p<0.05$, J20 compared with WT; \#p $<0.05$, J20.SK2 $\Delta$ compared with WT.

pling (Tort et al., 2010; Fig. 2I). The decrease in the modulation index in 20 compared with WT $(p=0.075)$ and $\mathrm{J} 20 . \mathrm{SK} 2 \Delta(p=$ $0.070)$ mice was close to statistical significance as determined by Sidak's post-test following one-way ANOVA. Co-modulation analysis of $\gamma$ amplitude along $\theta$ phase showed similar phase lock of amplitude modulation between recordings from all genotypes (Fig. 2I). However, peak amplitude modulation was significantly lower in J20 compared with WT mice (Fig. 2I).

SK2 deletion synergizes with the $A P_{S_{w I n d}}$ transgene to produce recognition memory deficits

Familial AD mouse models such as J20 are characterized by deficits in spatial and recognition memory that often precede overt A $\beta$ plaque deposition (Karl et al., 2012; Verret et al., 2012; Cheng et al., 2013; Beauquis et al., 2014). In the Y-maze, a common test of spatial reference memory, the percentage of entries into the novel arm (Fig. $3 A$ ) and distance traveled in the novel arm (Fig. $3 B$ ) were significantly higher than expected by chance for WT, SK2 $\Delta$, and $\mathrm{J} 20$ mice, indicating their memory of the familiar arms of the maze and motivation to explore the novel arm. In contrast, the percentage of entries into, and distance traveled in, the novel arm were not significantly higher than expected by chance for J20.SK2 $\Delta$ mice. The SPT assesses the preference for exploration of a cage containing a mouse compared with an empty cage (i.e., sociability), while the SNT assesses the innate preference for exploring a new over a familiar mouse (social recognition memory; Cheng et al., 2013). These tests were applied to two distinct cohorts of mice, one 7 months and the other 12 months of age. All four genotypes exhibited a statistically significant preference for the inhabited over the empty cage in the SPT, with the exception of $\mathrm{J} 20$ mice at 12 months of age (Fig. $3 C, D)$. In the SNT, J20 mice performed less well than WT, but nonetheless spent significantly more time exploring the novel over the familiar mouse at both 7 and 12 months of age (Fig. $3 E, F)$. In contrast, J20.SK2 $\Delta$ mice did not spend significantly more time exploring the novel mouse at either age. In the NORT (Karl et al., 2012), only the WT mice showed a preference for the novel object at 7 months of age (Fig. $3 G$ ). None of the strains showed a statistically significant preference for the novel object at 12 months of age (Fig. 3H). 
Loss of hippocampal volume in J20.SK2 $\Delta$ mice

On the basis of the cognitive deficits and suppressed PSD in J20.SK2 $\Delta$ mice, we investigated hippocampal volume and neuronal density. The volume of the dentate gyrus (DG) and cornu ammonis (CA) regions of the hippocampus were significantly altered as a function of genotype in 13-month-old mice $(F=4.8, p=0.014$ for DG; $F=3.5, p=0.036$ for CA by one-way ANOVA). DG volume was $24 \%$ lower in 13-month-old J20 compared with WT mice (not significant), and 34\% lower in J20.SK $2 \Delta$ ( $p=0.016$; Fig. $4 A$ ). CA volume was not reduced in J20 mice but $29 \%$ lower in J20.SK2 $\Delta$ compared with WT mice $(p=0.030$; Fig. $4 B)$. There was no effect of genotype on the volume of the DG (Fig. $4 C)$ or CA $(4 D)$ regions in 8 -month-old mice $(F=1.4, p=0.26$ for DG; $F=0.6, p=0.61$ for CA by one-way ANOVA). The area of staining for the neuronal marker NeuN was not reduced in hippocampal sections from 13-monthold J20.SK $2 \Delta$ mice $(F=0.21, p=0.89$; Fig. $4 E, F)$, suggesting that loss of hippocampal volume cannot be attributed to a loss of neurons. This was also true when broken down into DG $(F=0.2, p=0.92)$ and $\mathrm{CA}(F=1.3, p=0.31)$. However, the NeuN-negative area, which does not contain neuronal cell bodies, decreased as a proportion of total hippocampal area in $\mathrm{J} 20 . \mathrm{SK} 2 \Delta$ mice $(F=3.84, p=0.029$ by one-way ANOVA; Fig. $4 G)$.

Hypomyelination precedes A $\beta$ deposition in J20.SK2 $\Delta$ mice Having observed reduced hippocampal volume in J20.SK2 $\Delta$ mice, we investigated the levels of neurofilament-H (NF-H), a marker of neuronal processes, and the myelin marker myelin basic protein (MBP), using immunofluorescence microscopy. Although reduced MBP immunoreactivity was observed in the hippocampus and cortex of 13 -month-old SK2 $\Delta$ mice, there was stark loss of MBP staining in J20.SK2 $\Delta$ mice (Fig. 5A-H). NF-H staining was apparent in the absence of MBP staining. MBP staining was not appreciably different between the four genotypes in the cerebellum (Fig. 5I-L). MBP staining also appeared to be reduced in the hippocampus of J20.SK2 $\Delta$ but not J20 or SK2 $\Delta$ mice at 8 months of age (Fig. $5 M-P$ ).

Western blotting was performed to provide more quantitative data on myelin content in the hippocampus and cortex. In the cortex of 8-month-old mice, the levels of $\mathrm{MBP}(F=3.1, p=$ $0.051)$, myelin proteolipid protein (PLP; $F=2.7, p=0.07)$, and myelin oligodendrocyte glycoprotein (MOG; $F=6.9, p=0.002$ ) were affected by genotype (Fig. $6 A, B$ ). Compared with WT mice, MBP, PLP, and MOG were $60 \%(p=0.027), 37 \%(p=0.051)$, and $55 \%(p=0.001)$ lower, respectively, in J20.SK2 $\Delta$ mice; and MOG was $44 \%$ lower $(p=0.011)$ in J20 mice. Similar loss of $\operatorname{MBP}(76 \%, p=0.046), \operatorname{PLP}(55 \%, p=0.092)$, and MOG $(55 \%$, $p=0.077)$ was observed in the cortex of 13-month-old J20.SK2 $\Delta$ mice. In the hippocampus, there was no notable effect of genotype on these myelin markers at 8 months, however, all three were appreciably lower in J20.SK2 $\Delta$ mice at 13 months of age. The significant.
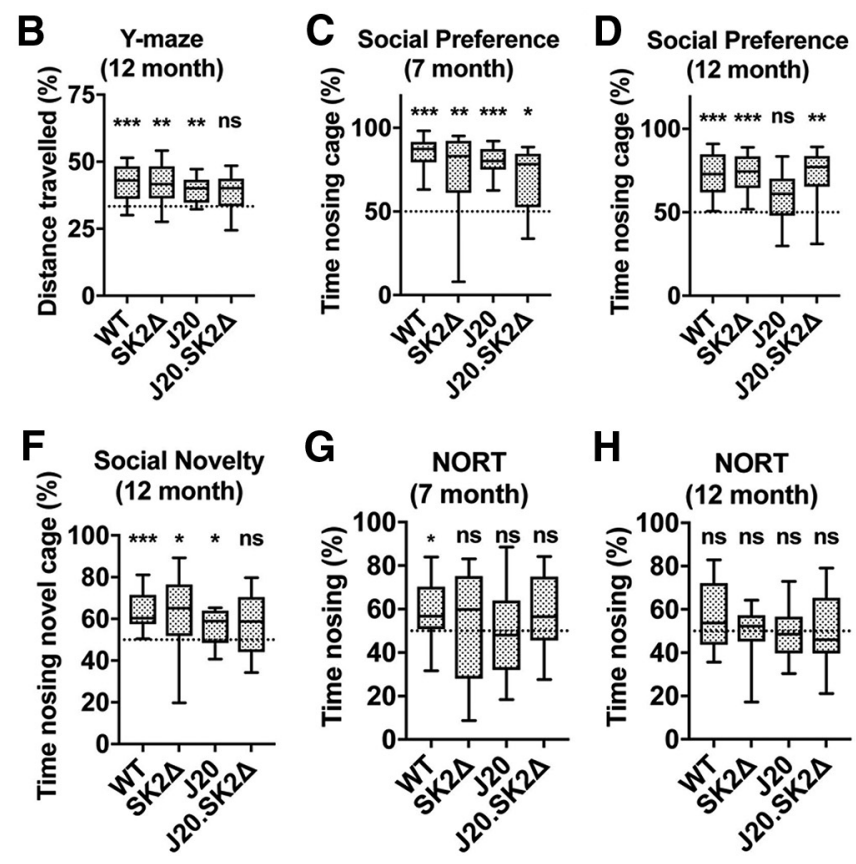

Figure 3. J20.SK2 $\Delta$ mice exhibit deficits in recognition memory. $\boldsymbol{A}$, Entries into, and $(\boldsymbol{B})$ distance traveled in, the novel arm of the $Y$-maze as a percentage of total arm entries and total distance traveled. $C, D$, Time spent nosing the inhabited cage, expressed (inhabited + uninhabited), in the SPT.E, F, Time spent nosing the cage with the novel mouse, expected by chance (dotted line) for each genotype ( $n=10-14$ mice per group). ${ }^{*} p<0.05,{ }^{* *} p<0.01,{ }^{* * *} p<0.001$; ns, not

effect of genotype on MBP levels in the hippocampus of 13month-old mice was statistically significant $(F=4.1, p=0.019)$, with a $66 \%$ reduction $(p=0.009)$ in J20.SK $2 \Delta$ relative to WT mice. Mean levels of all three myelin markers were lower in the hippocampus and cortex of both $\mathrm{J} 20$ and SK2 $\Delta$ mice at 13 months of age, however, this was not statistically significant. In all cases, myelin markers were lowest in J20.SK2 $\Delta$ mice, indicating a synergistic effect of SK2 deletion and $\mathrm{APP}_{\mathrm{SwInd}}$ transgene on myelin content. The neuronal markers neurofilament $\mathrm{H}$ and $\beta I I I$ tubulin were not depleted in J20.SK2 $\Delta$ mice (Fig. $6 C, D$ ), indicating that demyelination is not secondary to axonal degeneration.

To determine whether myelin loss results from loss of oligodendrocytes, we quantified Olig2-positive cells in the hippocampus (Fig. 6E). Two-way ANOVA demonstrated a significant effect of both age $(F=7.3, p=0.01)$ and genotype $(F=3.3, p=$ 0.03 ) on oligodendrocyte density. Numbers were not significantly different between genotypes at 8 months of age. However, at 13 months of age, mean oligodendrocyte density was $26 \%$ lower in SK2 $\Delta(p=0.29), 39 \%$ lower in $\mathrm{J} 20(p=0.072)$, and $51 \%$ lower in J20.SK2 $\Delta(p=0.014)$ compared with WT mice. Reduced oligodendrocyte density in the hippocampus of 13-month-old J20.SK2 $\Delta$ mice was confirmed by quantifying cells positive for the mature oligodendrocyte marker aspartoacylase (ASPA): ASPApositive cell number differed by $<10 \%$ (not significant) between WT, SK $2 \Delta$, and J20, but was $41 \%$ lower in the hippocampus of J20.SK2 $\Delta$ compared with WT mice $(p=$ 0.008 ; 4 mice per group). These results indicate that the J20 transgene and SK2 deficiency act synergistically to deplete oligodendrocytes and create a severe myelin deficit in the hippocampus and cortex. 
A

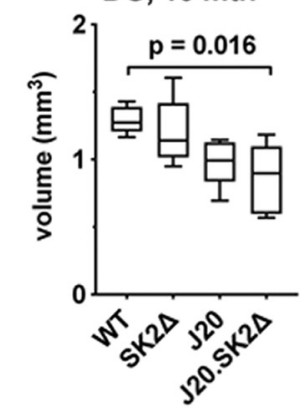

B CA1-CA3, $13 \mathrm{mth}$

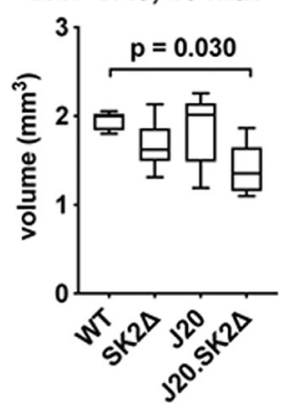

E

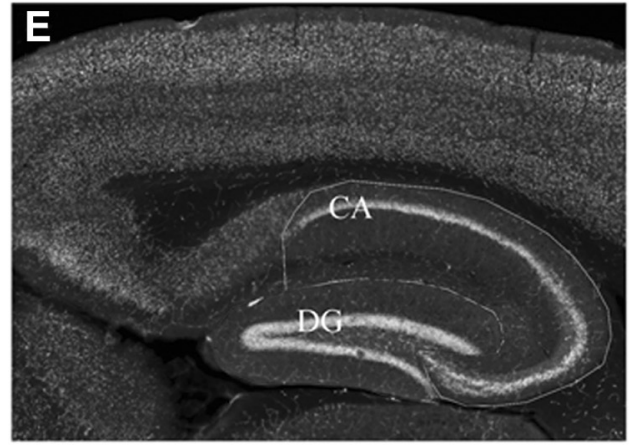

C

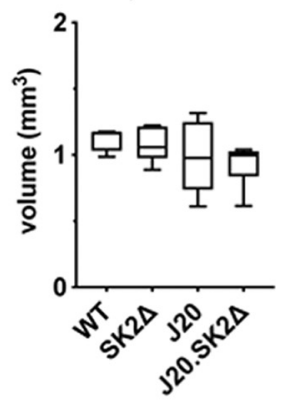

F NeuN positive area

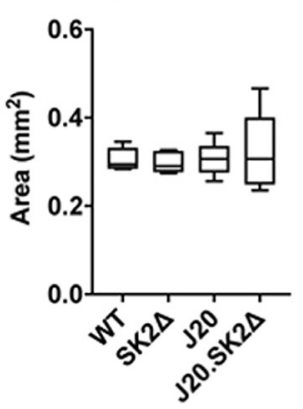

D CA1-CA3, 8 mth

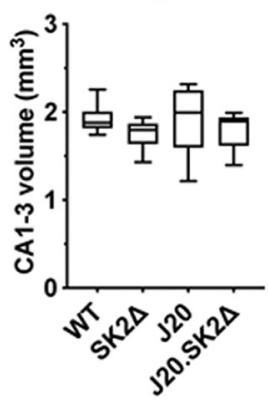

G NeuN negative (\%)

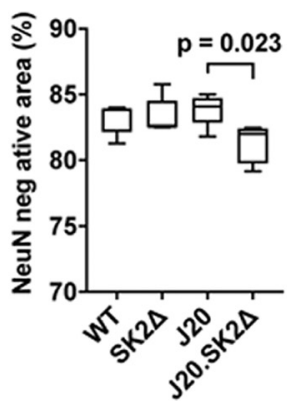

Figure 4. Loss of hippocampal volume in J20.SK2 $\Delta$ mice. $\boldsymbol{A}-\boldsymbol{D})$ Estimated volume of the $D G(\boldsymbol{A}, \boldsymbol{C})$ and $(\mathrm{A} 1$-3 region $(\boldsymbol{B}, \boldsymbol{D})$ of the hippocampus in 13-month-old $(\boldsymbol{A}, \boldsymbol{B})$ and 8-month-old $(\boldsymbol{C}, \boldsymbol{D})$ mice. mth, Month. $\boldsymbol{E}$, NeuN staining of a WT mouse hippocampus with CA and DG regions outlined. $\boldsymbol{F}$, Mean NeuN-positive area of the hippocampus in 13-month-old mice. $\boldsymbol{G}$, NeuN-negative area as a percentage of total hippocampal area in 13-month-old mice. Statistical significance was determined by one-way ANOVA with Sidak's post-test (5-6 mice per group). ANOVA results reported in-text with significant post-test results shown on the graphs.

\section{SK2 activity and S1P levels are affected by lysosomal dysfunction}

Although we and others have demonstrated loss of S1P (He et al., 2010; Couttas et al., 2014) and SK2 activity (Couttas et al., 2014) in $\mathrm{AD}$ brain tissue specimens, brain S1P levels were not reduced in J20 mice at 13 months of age (Fig. 7A). In fact, SK2 activity trended higher in the hippocampus of 13 month $J 20$ compared with WT mice (Fig. $7 B ; t=1.69, p=0.12$ by $t$ test). NFT pathology is another pathological hallmark of $\mathrm{AD}$, and aggregationprone mutant forms of tau cause pronounced neuron loss in frontotemporal dementia. However, there was no notable difference in S1P and sphingosine levels, or the S1P:sphingosine ratio, in cortical tissue from the very aggressive tau(K369I) mouse model at 6 months of age, when abundant NFT pathology is present ( L. M. Ittner et al., 2008). S1P/sphingosine ratios were $0.77 \pm 0.17$ and $0.79 \pm 0.15$ in tau(K369I) mice and their WT littermates (mean \pm SEM, $n=8$ per group). There was also no significant effect of the tau(K369I) transgene on SK2 activity $(28.5 \pm 6.4 \mathrm{fmol} \mathrm{S1P} / \mathrm{min} / \mu \mathrm{g}$ protein in tau(K369I) and $41.9 \pm$ 5.7 in WT mice). Supported by previously-published results with the APP ${ }^{\mathrm{Sw}} / \mathrm{PS} 1{ }^{\Delta \mathrm{Eg}}$ mouse model (Couttas et al., 2014), these results suggest that loss of $\mathrm{S} 1 \mathrm{P}$ in $\mathrm{AD}$ is not a direct consequence of $\mathrm{A} \beta$ or tau pathology.

Dysfunction of the endosomal-lysosomal system associated with enlarged endosomes and autolysosomes is another pathological trait of $\mathrm{AD}$ that is central to $\mathrm{A} \beta$ production and deposition (Morel et al., 2013; Nixon, 2017), particularly as mutations in genes directly involved in endosomal and lysosomal processes (BIN1, PICALM, SORL1, APOE) enhance the risk for late-onset AD (Karch and Goate, 2015; Nuriel et al., 2017). Niemann-Pick type C (NPC) disease is caused by loss of function of the late endosomal/lysosomal cholesterol transporter NPC1, leading to lysosomal dysfunction and lipid storage. Importantly, neurofibrillary tangles and $\mathrm{A} \beta$ accumulation are observed in NPC cases and mouse models, suggestive of a similar etiology to $\mathrm{AD}$ (Saito et al., 2002; Jin et al., 2004). Treating the oligodendrocyte cell line MO3.13 with the NPC1 inhibitor U18666A reduced mean S1P content by $59 \%(F=4.5, p=0.045$ by one-way ANOVA $)$ and increased sphingosine levels twofold at $48 \mathrm{~h}(F=95.2, p<$ 0.0001; Fig. 7C). Thus, the S1P:sphingosine ratio decreased $46 \%$ at $24 \mathrm{~h}$, and $78 \%$ at $48 \mathrm{~h}(F=13.4, p=0.002)$. This was associated with $41 \%$ and $59 \%$ reductions in mean SK2 activity at 24 and $48 \mathrm{~h}$ of treatment $(F=5.46, p=0.028$; Fig. $7 D)$. It has been proposed that astrocytes are the major source of sphingosine kinase activity in the brain (Blondeau et al., 2007). The decline in S1P-sphingosine ratio with U18666A was also observed in the human astrocytoma cell line U251 $(F=37.6, p<0.0001)$ and primary human astrocytes $(F=5.6, p=0.027)$, as well as mouse oligodendrocyte cell line Oli-neu $(F=4.8, p=0.037)$. A near-significant decline was observed in the neuronal cell line SH-SY5Y $(F=3.7, p=$ 0.067; Fig. 7E).

De-acidification of endosomes and lysosomes with $\mathrm{NH}_{4} \mathrm{Cl}$ (which inhibits the activity of lipases and proteases that require acidic $\mathrm{pH}$ ), and inhibition of serine and cysteine proteases with the protease inhibitor leupeptin, both impede autophagosome and lysosome flux and increase amyloidogenic processing of APP by $\beta$ - and $\gamma$-secretases (Boland et al., 2010; Tamboli et al., 2011; Cermak et al., 2016). $\mathrm{NH}_{4} \mathrm{Cl}$ treatment rapidly depleted both S1P and sphingosine (Fig. $7 F$ ), whereas inhibition of lysosomal proteases with leupeptin had no effect on either (Fig. 7G). Accumulation of the autophagosome marker LC3B-II demonstrated that all three treatments effectively impaired autophagosome turnover in the time frame investigated (Fig. $7 \mathrm{H}$ ). These results indicate that perturbing lipid metabolism in late endosomes, but not 


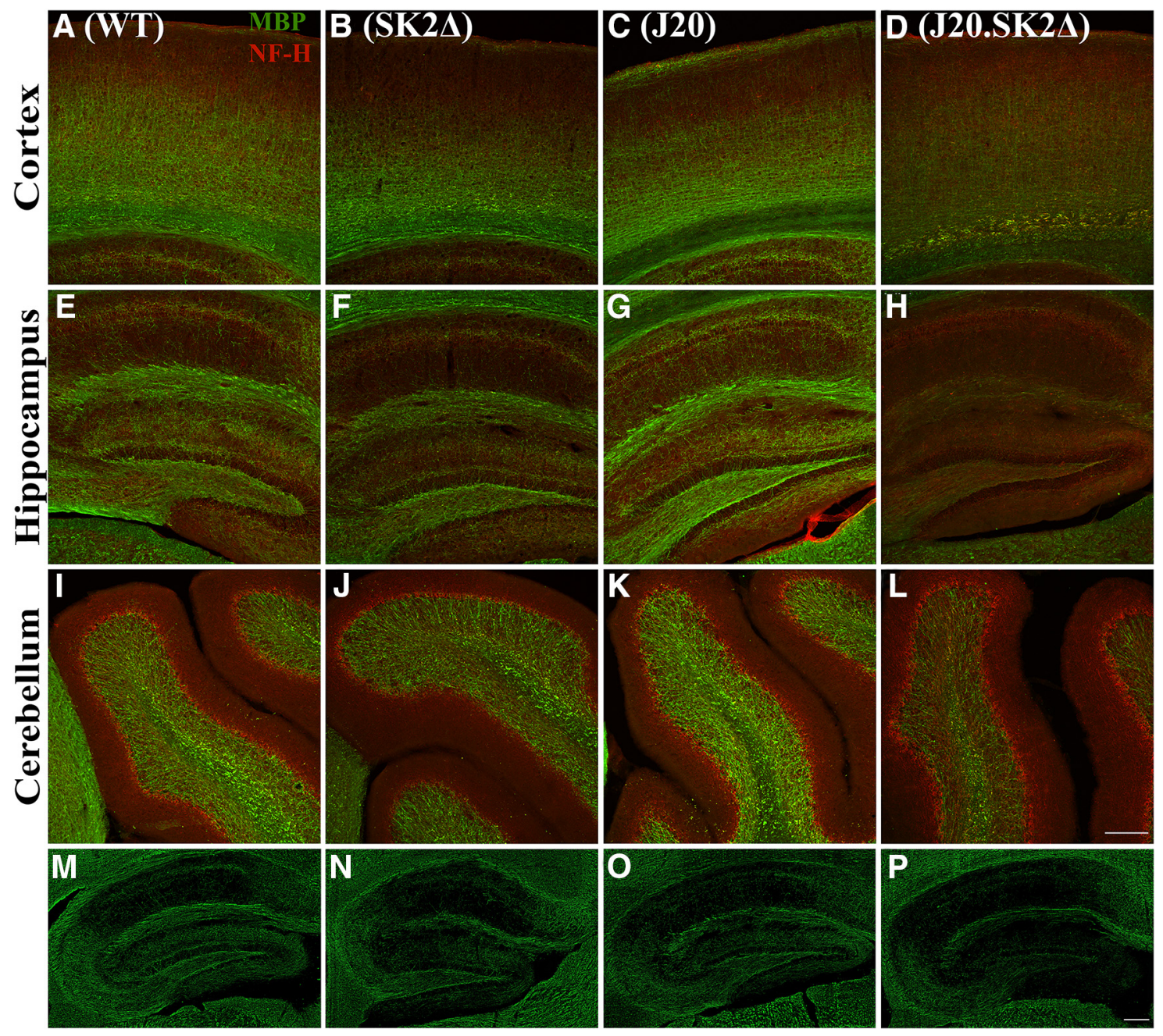

Figure 5. Pronounced hypomyelination in J20.SK2 $\Delta$ mice. $\boldsymbol{A}-\boldsymbol{L}$, Immunofluorescence for MBP (green) and NF-H (red) in the cortex $(\boldsymbol{A}-\boldsymbol{D})$, hippocampus $(\boldsymbol{E}-\boldsymbol{H})$, and cerebellum $(\boldsymbol{I}-\boldsymbol{L})$ of 13-month-old WT $(A, E, I)$, SK2 $\Delta(B, F, J), J 20(C, G, K)$, and J20.SK2 $\Delta$ mice $(\boldsymbol{D}, \boldsymbol{H}, \boldsymbol{L})$. M-P, MBP immunofluorescence in the hippocampus of 7-month-0ld WT (M), SK2 $\Delta(\boldsymbol{N})$, J20 (O) , or J20.SK2 $\Delta$ mice $(\boldsymbol{P})$. Scale bar, $200 \mu \mathrm{m}$.

generalized interference with lysosomal function, leads to the depletion of S1P relative to sphingosine and disruption of SK2 activity.

\section{Discussion}

This study investigated whether loss of SK2 sensitizes to A $\beta$ mediated neurodegeneration. We show for the first time that SK2 deletion greatly reduces $A \beta$ formation in vivo, and corrects $A \beta$ dependent epileptiform activity. However, SK2 deficiency acted synergistically with the $\mathrm{APP}_{\text {SwInd }}$ transgene to cause age-dependent loss of myelin and hippocampal volume, a significant suppression of spectral power measured by EEG, and cognitive deficits, indicating that SK2 is neuroprotective in the context of AD.

Our finding that endogenous SK2 is required for $A \beta$ formation from APP in vivo confirms the results of a prior study showing the same in cultured neurons (Takasugi et al., 2011); these authors proposed that S1P directly stimulates Bacel activity in vitro. APP cleavage by Bacel occurs in endosomes (van der Kant and Goldstein, 2015). Both SK1 and SK2 are present in endosomes, where they are functionally important for recycling of internalized macromolecules (Shen et al., 2014; Lima et al., 2017). Marked depletion of S1P following disruption of endosomal cholesterol export with U18666A, or de-acidification of endosomes and lysosomes with $\mathrm{NH}_{4} \mathrm{Cl}$, implies that the bulk of cellular $\mathrm{S} 1 \mathrm{P}$ is generated from sphingosine in acidic endosomes, where, in theory, it can directly stimulate Bacel. $\mathrm{NH}_{4} \mathrm{Cl}$ also reduced sphingosine, suggesting that acid ceramidase activity, which is increased in $\mathrm{AD}$ (He et al., 2010), is the major cellular source of sphingosine. Our results with U18666A are in agreement with a prior study showing selective depletion of S1P relative to sphingosine in NPC1-deficient neurons (Lee et al., 2014). Intracellular S1P is rapidly turned over by S1P lyase and S1P-specific phosphatases Sgpp1/2, so any reduction in SK2 activity might be expected to produce a large effect on S1P-sphingosine balance.

A strong body of genetic and neuropathological evidence implicates both impaired cellular cholesterol metabolism and altered endosomal membrane composition and trafficking in the etiology of AD (Morel et al., 2013; Karch and Goate, 2015; Nixon, 2017; Nuriel et al., 2017). Inability to properly process cholesterol esters in endosomes (R. B. Chan et al., 2012b; van der Kant et al., 2019) and export cholesterol to lipoproteins (Nordestgaard et al., 2015; Yassine et al., 2016) are common features of both $\mathrm{AD}$ and NPC disease. Thus, both diseases are characterized by accumulation of $\mathrm{A} \beta$ and hyperphosphorylated tau (Saito et al., 2002; Jin et al., 2004). We speculate that loss of SK2 function and S1P in AD 

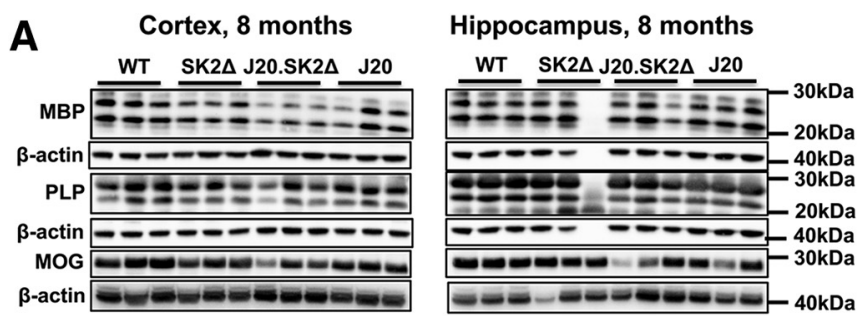

B
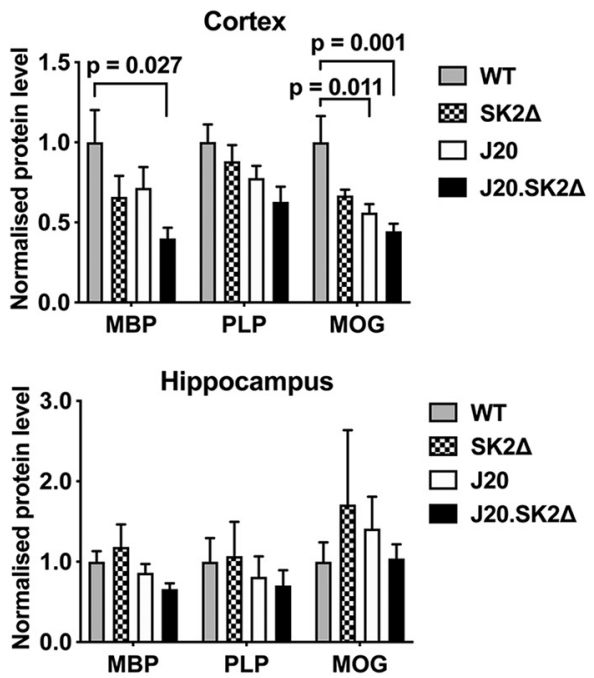

E

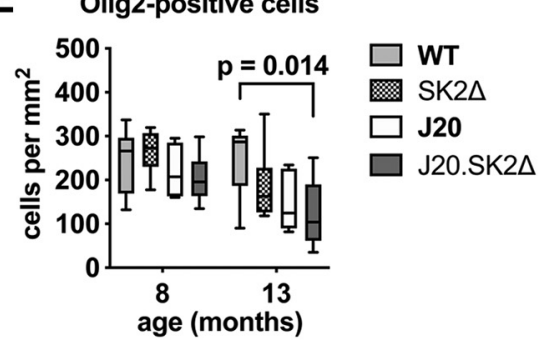

C Cortex, 13 months

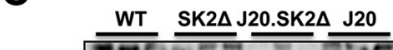

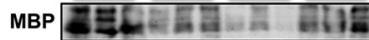

$\beta$-actin m-anempram

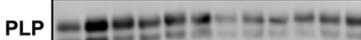

$\beta$-actin

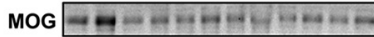

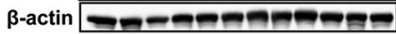

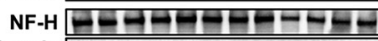

$\beta$-actin $=--\infty-\infty-m-m-m$

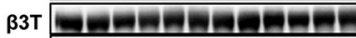

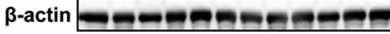

D
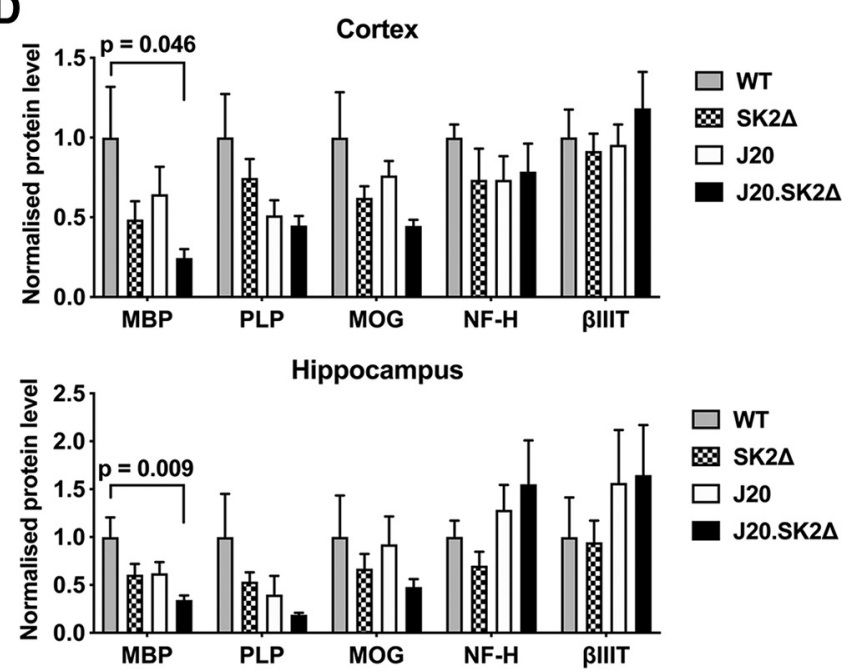

Hippocampus, 13 months

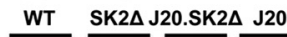

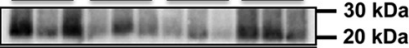

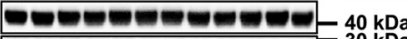

늘
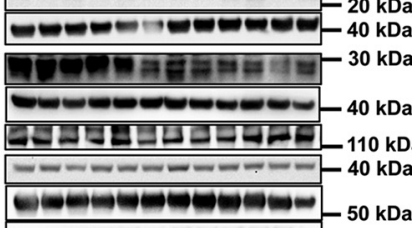

Figure 6. Loss of myelin markers and reduced oligodendrocyte density in J20.SK2 $\Delta$ mice. Western blots $(\boldsymbol{A}, \boldsymbol{C})$ and densitometric quantification $(\boldsymbol{B}, \boldsymbol{D})$ of myelin and neuronal markers in cortex and hippocampus of 8-month-old $(\boldsymbol{A}, \boldsymbol{B})$ and 13-month-old $(\boldsymbol{C}, \boldsymbol{D})$ mice. Protein levels were normalized to $\beta$-actin in each sample, then to the mean of the control group. Graphs show mean \pm SEM; $n=5-6$ mice per genotype. Statistical significance was determined by one-way ANOVA with Sidak's post-test. E, Olig2-positive cell density in the hippocampus (mean \pm SEM; $n=5-6$ ). Statistical significance was determined by two-way ANOVA with Dunnett's post-test. $P$ values for comparisons that were significant in post-tests $(p<0.05)$ are shown on the graphs.

is attributed to the altered lipid environment of endosomal membranes. This could impair SK2 recruitment to endosomes, a possibility that will be investigated in future studies, and may explain redistribution of SK2 from cytosol to nucleus in neurons of AD brains (Dominguez et al., 2018).

SK2 deficiency abated hippocampal epileptiform activity in J20 mice, supporting prior research showing that this hyperexcitatory activity is $\mathrm{A} \beta$-dependent (Verret et al., 2012; A. Ittner et al., 2014). Deficits in $\theta$ - $\gamma$ cross frequency coupling were also reduced, in agreement with recent work indicating that neurotoxic $\mathrm{A} \beta$ signaling at synaptic junctions impairs this measure of network activity (A. Ittner et al., 2016). It has been reported that abnormal EEG activity is dependent on APP overexpression rather than $\mathrm{A} \beta$, based on the lack of any effect of $\gamma$-secretase inhibition (Born et al., 2014). Our results argue that the epileptiform activity and network aberrations are dependent on $A \beta$, or possibly the $\beta$-C-terminal fragment of APP generated by Bace1, because APP expression was equivalent in J20 and J20.SK2 $\Delta$. The statistically significant reduction in $\gamma$-oscillation power in J20.SK2 $\Delta$ but not J20 mice indicates that this measure is uncoupled from $\mathrm{A} \beta$ levels. Loss of spectral power could be a consequence of extensive demyelination in J20.SK2 $\Delta$ mice, as suggested for parvalbumin interneurons in schizophrenia (Stedehouder and Kushner, 2017).

Marked loss of hippocampal volume, myelin, and oligodendrocytes was observed in 13-month-old, but not 8-month-old J20.SK $2 \Delta$ mice, indicating that these are age-dependent phenotypes temporally associated with $\mathrm{A} \beta$ plaque deposition in the J20 model. Neurite markers NF-H and $\beta$ III-tubulin were not reduced in 13-month-old J20.SK2 $\Delta$ mice, whereas myelin markers were, suggesting that reduced hippocampal volume is at least partly a result of myelin loss. Myelin loss has been reported as an early pathological feature in several AD mouse models (Desai et al., 2009; Behrendt et al., 2013), preceding A $\beta$ plaque deposition in the $3 \times$ Tg model (APP, PS1, and tau mutant transgenes; Desai et al., 2009). In our model, MBP and MOG were significantly reduced in the cortex of J20.SK $2 \Delta$ mice at 8 months, before notable $\mathrm{A} \beta$ plaque pathology, and sustained at 13 months. However, significant loss of myelin markers and oligodendrocytes in the hippocampus was only observed at 13 months. Myelin mark- 

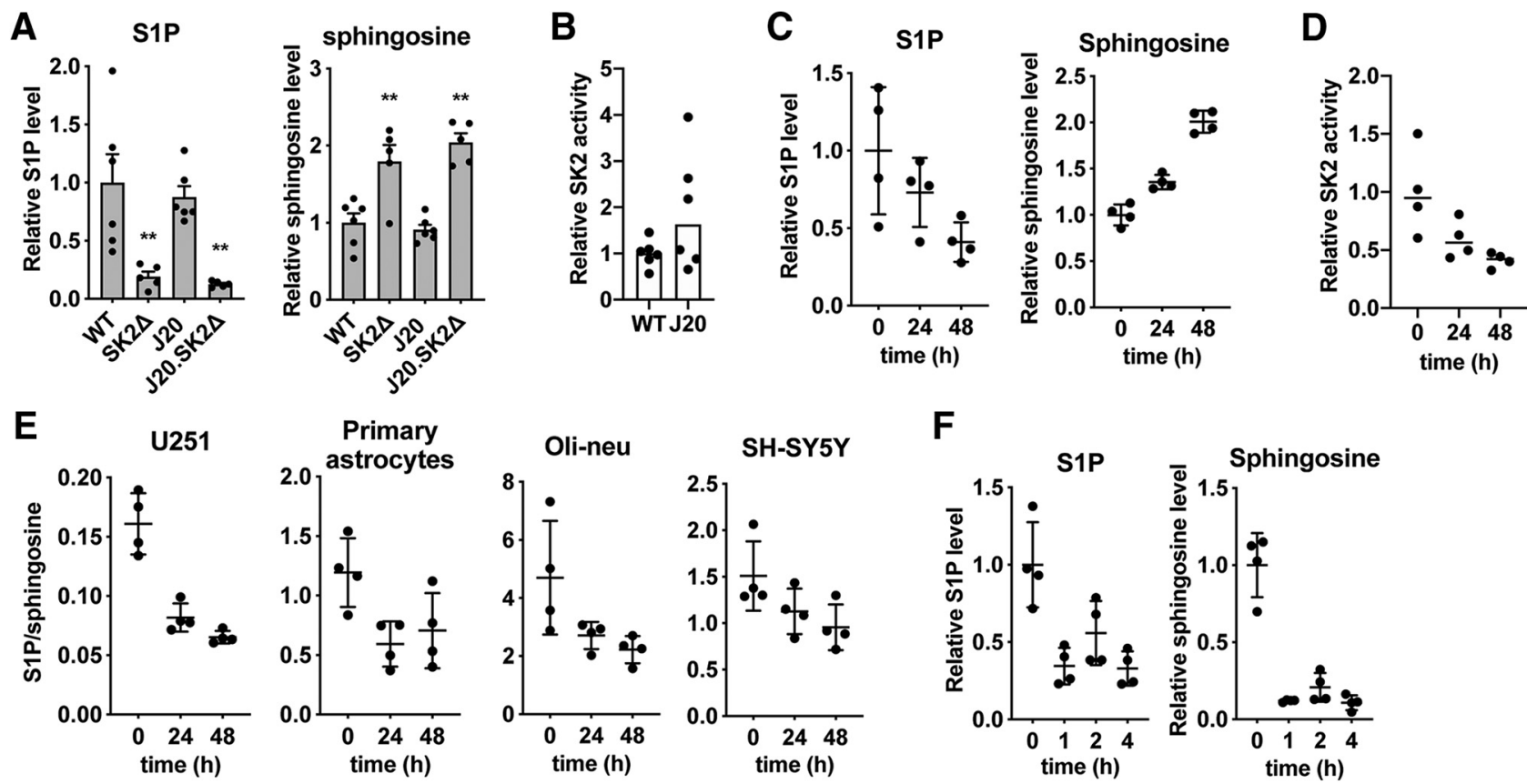

$\mathbf{F}$
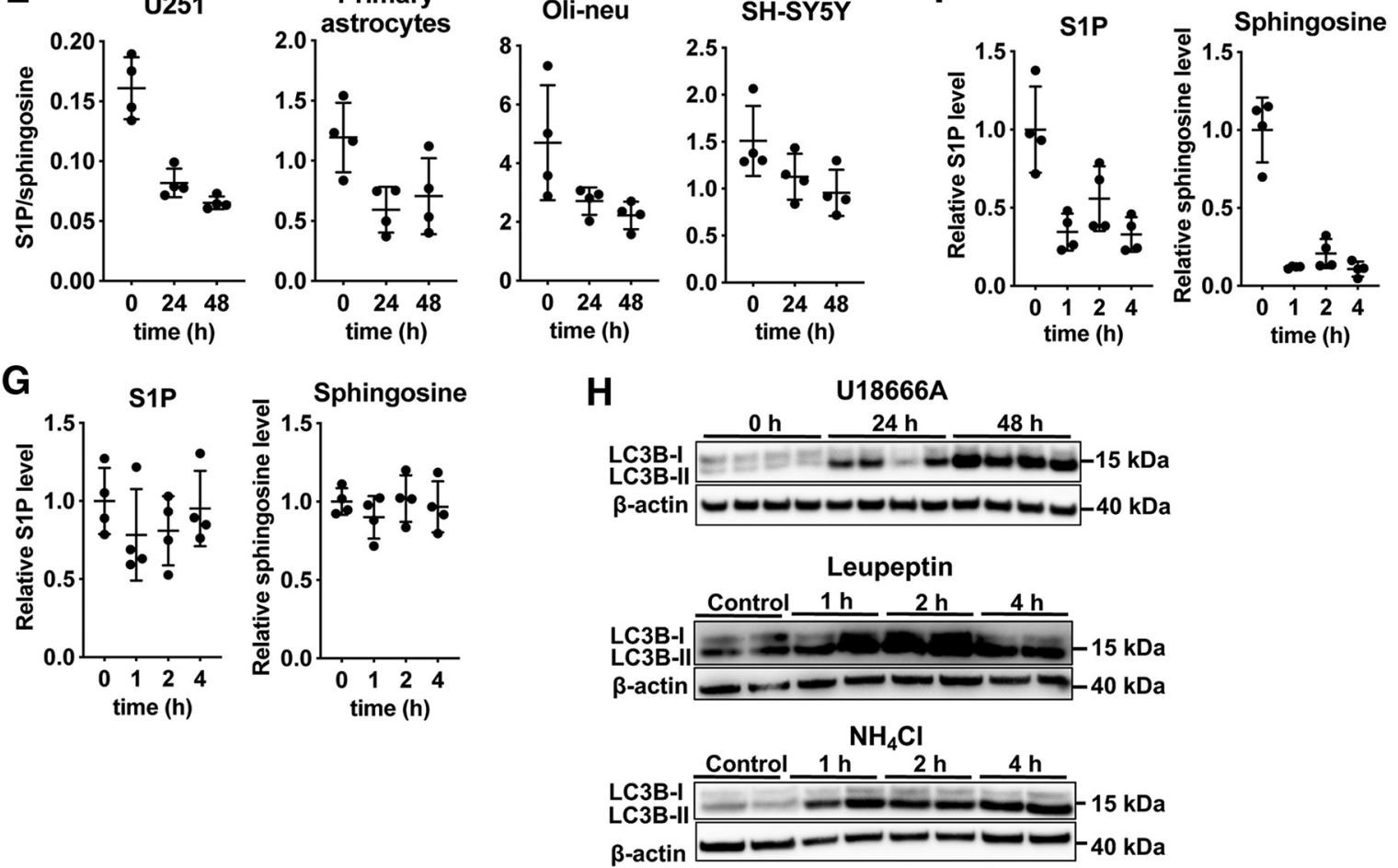

Figure 7. Inhibition of endosomal cholesterol export affects sphingosine phosphorylation. $A$, Levels of S1P and sphingosine in the cortex of 13-month-old WT, SK2 $\Delta$, J20, and J20.SK2 $\Delta$ mice (5-6 mice per group). Statistical significance was determined by one-way ANOVA followed by Sidak's post-test, ${ }^{* *} p<0.01$. ANOVA results for $S 1 P: F=9.7 ; p=0.0005 ;$ sphingosine: $F=17.7$, $p<0.0001$. B, SK2 activity in hippocampus of 13-month-old WT or J20 mice (6 mice per group). Activity is normalized to the mean of the WT group. C, S1P and sphingosine, and (D) SK2 activity, in M03.13 cells treated with $3 \mu \mathrm{g} / \mathrm{ml}$ U18666A. Levels are normalized to the mean of the zero time point. E, S1P/sphingosine ratio in U251 cells, primary astrocytes, Oli-neu cells, or SH-SY5Y cells treated with $3 \mu \mathrm{g} / \mathrm{ml}$ U18666A. $\boldsymbol{F}, \mathbf{G}, \mathrm{S} 1 \mathrm{P}$ and sphingosine in M03.13 cells treated with $(\boldsymbol{F}) 5 \mathrm{~mm} \mathrm{NH}_{4} \mathrm{Cl}$ or $(\boldsymbol{G}) 100 \mu \mathrm{m}$ leupeptin. Statistical significance in $\boldsymbol{B}-\boldsymbol{G}$ was determined by one-way ANOVA and reported in the results text. Each experiment involved four independent cell treatments. $\boldsymbol{H}$, Western blots showing LC3B-I (top band) and LC3B-II (bottom band) protein levels, with $\beta$-actin as a loading control, in M03.13 cells treated with U18666A, leupeptin, or $\mathrm{NH}_{4} \mathrm{Cl}$.

ers were also consistently lower in J20 and SK2 $\Delta$ compared with WT mice. However, with the exception of MOG in the cortex of 8-month-old J20 mice, this was not statistically significant. It is clear that SK2 deletion and the $\mathrm{APP}_{\text {SwInd }}$ transgene acted synergistically in affecting oligodendrocyte number, myelin content, and hippocampal volume. Marked loss of myelin markers (Wallin et al., 1989; Han et al., 2002; Couttas et al., 2016) and Olig2positive cells (Behrendt et al., 2013) has been reported in AD cases, verifying the clinical relevance of the findings in our mouse model.

We propose that the absence of SK2 hyper-sensitizes oligodendrocytes to excitotoxic $A \beta$, causing cell death; and speculate that the level of soluble $\mathrm{A} \beta$ in J20.SK2 $\Delta$ mice reaches a threshold that is sufficient to precipitate oligodendrocyte attrition and myelin loss, despite being lower than in J20 mice with functional SK2. Although $\mathrm{A} \beta$ plaques are not common in white matter, soluble $\mathrm{A} \beta$ levels are significantly higher in white matter of $\mathrm{AD}$ cases compared with controls (Collins-Praino et al., 2014), and oligodendrocytes are prone to $\mathrm{A} \beta$-induced cell death (Xu et al., 2001). Although we cannot rule out the possibility that expression of the $\mathrm{APP}_{\text {SwInd }}$ transgene, in combination with SK2 deficiency, adversely affects oligodendrocyte survival and myelin through a mechanism other than $\mathrm{A} \beta$ toxicity, prior research showed that the myelin deficit in the $3 \times \mathrm{Tg}$ mouse model is corrected when the mice are treated with an intrabody that clears $\mathrm{A} \beta$ (Desai et al., 2010). Further experiments are needed to determine whether the neuroprotective properties of SK2 in J20 mice are mediated through S1P receptor signaling, intracellular actions of S1P, or both. S1P promotes oligodendrocyte survival through S1PR1 and S1PR5 receptor signaling (Jaillard et al., 2005), and the S1P receptor agonist fingolimod protects oligodendrocyte survival in the face of proapoptotic stimuli (Coelho et al., 2007; Kim et al., 2011). On the other hand, S1P generated by nuclear-localized SK2 promotes neurotrophic 
signaling and neuronal plasticity via inhibition of histone deacetylases (Hait et al., 2014).

The contribution of oligodendrocyte dysfunction and demyelination to $\mathrm{AD}$ pathogenesis has been under-investigated. Myelin degeneration triggers neurodegeneration, including NFT pathology in neurons (Griffiths et al., 1998; Anderson et al., 2008). The pattern of NFT development in AD runs inverse to the course of developmental myelination (Braak and Braak, 1996) and we have shown a significant deficiency in the myelin lipid biosynthetic enzyme CerS2 that precedes NFT pathology in the cerebral cortex (Couttas et al., 2016). Han et al. (2002) showed substantial loss of the myelin lipid sulfatide at the mild cognitive impairment, pre-AD stage, and MRI studies show that white matter changes precede gray matter atrophy in $\mathrm{AD}$ (Agosta et al., 2011; Selnes et al., 2012; Zhuang et al., 2013). Oligodendrocytes are important not only for the synthesis of myelin, but also for the provision of essential metabolic and trophic support to neurons (Simons and Nave, 2016).

The results of our cognitive tests support the hypothesis that SK2 deficiency synergizes with $A \beta$ to promote a neurodegenerative phenotype. Only J20.SK2 $\Delta$ mice exhibited a statistically significant deficit in the Y-maze and SNT, the latter in two distinct cohorts of mice ( 7 and 12 months old). Deficient social behavior cannot explain the social recognition memory deficit, as J20.SK2 $\Delta$ mice showed intact sociability in the SPT. These memory deficits may be at least partly attributed to demyelination. Single nucleotide polymorphisms in, and expression levels of, oligodendrocyte genes are strongly associated with cognitive speed and memory (Fields, 2008; Voineskos et al., 2013). White matter tract integrity is also directly associated with cognitive capability during development, in schizophrenia, and in AD (Fields, 2008; Selnes et al., 2012; Voineskos et al., 2013; Zhuang et al., 2013; Maas et al., 2017).

In conclusion, our results support the hypothesis that loss of S1P in normal aging (Couttas et al., 2018) and AD (He et al., 2010; Couttas et al., 2014) sensitizes to neurodegeneration. Similarly, loss of SK2 sensitizes to cerebral ischemia (Pfeilschifter et al., 2011). We demonstrate that SK2 is an endogenous regulator of $A \beta$ formation from APP, and uncover a new role for SK2 in maintaining oligodendrocyte survival and myelin content, urging greater consideration of age-dependent oligodendrocyte dysfunction and myelin loss in $\mathrm{AD}$ pathogenesis. Future research should examine the functional significance of reduced SK2 activity for endosome flux in neurons and glia, and determine whether the neuroprotective effects of SK2 in the context of AD are mediated through S1P receptors, which are established pharmacological targets for treatment of neurological diseases.

\section{References}

Agosta F, Pievani M, Sala S, Geroldi C, Galluzzi S, Frisoni GB, Filippi M (2011) White matter damage in Alzheimer disease and its relationship to gray matter atrophy. Radiology 258:853-863.

Alzheimer's Association (2019) 2019 Alzheimer's disease facts and figures. Alzheimers Dementia 15:321-387.

Anderson JM, Hampton DW, Patani R, Pryce G, Crowther RA, Reynolds R, Franklin RJ, Giovannoni G, Compston DA, Baker D, Spillantini MG, Chandran S (2008) Abnormally phosphorylated tau is associated with neuronal and axonal loss in experimental autoimmune encephalomyelitis and multiple sclerosis. Brain 131:1736-1748.

Beauquis J, Vinuesa A, Pomilio C, Pavía P, Galván V, Saravia F (2014) Neuronal and glial alterations, increased anxiety, and cognitive impairment before hippocampal amyloid deposition in PDAPP mice, model of Alzheimer's disease. Hippocampus 24:257-269.

Behrendt G, Baer K, Buffo A, Curtis MA, Faull RL, Rees MI, Götz M, Dimou
L (2013) Dynamic changes in myelin aberrations and oligodendrocyte generation in chronic amyloidosis in mice and men. Glia 61:273-286.

Bigaud M, Guerini D, Billich A, Bassilana F, Brinkmann V (2014) Second generation S1P pathway modulators: research strategies and clinical developments. Biochim Biophys Acta 1841:745-758.

Blondeau N, Lai Y, Tyndall S, Popolo M, Topalkara K, Pru JK, Zhang L, Kim H, Liao JK, Ding K, Waeber C (2007) Distribution of sphingosine kinase activity and mRNA in rodent brain. J Neurochem 103:509-517.

Boland B, Smith DA, Mooney D, Jung SS, Walsh DM, Platt FM (2010) Macroautophagy is not directly involved in the metabolism of amyloid precursor protein. J Biol Chem 285:37415-37426.

Born HA, Kim JY, Savjani RR, Das P, Dabaghian YA, Guo Q, Yoo JW, Schuler DR, Cirrito JR, Zheng H, Golde TE, Noebels JL, Jankowsky JL (2014) Genetic suppression of transgenic APP rescues hypersynchronous network activity in a mouse model of Alzheimer's disease. J Neurosci 34:3826-3840.

Braak H, Braak E (1995) Staging of Alzheimer's disease-related neurofibrillary changes. Neurobiol Aging 16:271-278; discussion 278-284.

Braak H, Braak E (1996) Development of Alzheimer-related neurofibrillary changes in the neocortex inversely recapitulates cortical myelogenesis. Acta Neuropathologica 92:197-201.

Buzsáki G, Moser EI (2013) Memory, navigation and theta rhythm in the hippocampal-entorhinal system. Nat Neurosci 16:130-138.

Cermak S, Kosicek M, Mladenovic-Djordjevic A, Smiljanic K, Kanazir S, Hecimovic S (2016) Loss of cathepsin B and L leads to lysosomal dysfunction, NPC-like cholesterol sequestration and accumulation of the key Alzheimer's proteins. PLoS One 11:e0167428.

Chan JP, Hu Z, Sieburth D (2012a) Recruitment of sphingosine kinase to presynaptic terminals by a conserved muscarinic signaling pathway promotes neurotransmitter release. Genes Dev 26:1070-1085.

Chan RB, Oliveira TG, Cortes EP, Honig LS, Duff KE, Small SA, Wenk MR, Shui G, Di Paolo G (2012b) Comparative lipidomic analysis of mouse and human brain with Alzheimer disease. J Biol Chem 287:2678-2688.

Cheng D, Logge W, Low JK, Garner B, Karl T (2013) Novel behavioural characteristics of the APP(Swe)/PS1DeltaE9 transgenic mouse model of Alzheimer's disease. Behav Brain Res 245:120-127.

Chételat G, La Joie R, Villain N, Perrotin A, de La Sayette V, Eustache F, Vandenberghe R (2013) Amyloid imaging in cognitively normal individuals, at-risk populations and preclinical Alzheimer's disease. Neuroimage Clin 2:356-365.

Choi JW, Chun J (2013) Lysophospholipids and their receptors in the central nervous system. Biochim Biophys Acta 1831:20-32.

Coelho RP, Payne SG, Bittman R, Spiegel S, Sato-Bigbee C (2007) The immunomodulator FTY720 has a direct cytoprotective effect in oligodendrocyte progenitors. J Pharmacol Exp Ther 323:626-635.

Collins-Praino LE, Francis YI, Griffith EY, Wiegman AF, Urbach J, Lawton A, Honig LS, Cortes E, Vonsattel JP, Canoll PD, Goldman JE, Brickman AM (2014) Soluble amyloid beta levels are elevated in the white matter of Alzheimer's patients, independent of cortical plaque severity. Acta Neuropathologica Commun 2:83.

Couttas TA, Kain N, Daniels B, Lim XY, Shepherd C, Kril J, Pickford R, Li H, Garner B, Don AS (2014) Loss of the neuroprotective factor sphingosine 1-phosphate early in Alzheimer's disease pathogenesis. Acta Neuropathol Commun 2:9.

Couttas TA, Kain N, Suchowerska AK, Quek LE, Turner N, Fath T, Garner B, Don AS (2016) Loss of ceramide synthase 2 activity, necessary for myelin biosynthesis, precedes tau pathology in the cortical pathogenesis of Alzheimer's disease. Neurobiol Aging 43:89-100.

Couttas TA, Kain N, Tran C, Chatterton Z, Kwok JB, Don AS (2018) Agedependent changes to sphingolipid balance in the human hippocampus are gender-specific and may sensitize to neurodegeneration. J Alzheimers Dis 63:503-514.

Desai MK, Sudol KL, Janelsins MC, Mastrangelo MA, Frazer ME, Bowers W] (2009) Triple-transgenic Alzheimer's disease mice exhibit region-specific abnormalities in brain myelination patterns prior to appearance of amyloid and tau pathology. Glia 57:54-65.

Desai MK, Mastrangelo MA, Ryan DA, Sudol KL, Narrow WC, Bowers WJ (2010) Early oligodendrocyte/myelin pathology in Alzheimer's disease mice constitutes a novel therapeutic target. Am J Pathol 177:1422-1435.

Dominguez G, Maddelein ML, Pucelle M, Nicaise Y, Maurage CA, Duyckaerts C, Cuvillier O, Delisle MB (2018) Neuronal sphingosine kinase 2 
subcellular localization is altered in Alzheimer's disease brain. Acta Neuropathol Commun 6:25.

Fields RD (2008) White matter in learning, cognition and psychiatric disorders. Trends Neurosci 31:361-370.

Goutagny R, Gu N, Cavanagh C, Jackson J, Chabot JG, Quirion R, Krantic S, Williams S (2013) Alterations in hippocampal network oscillations and theta-gamma coupling arise before $\mathrm{A} \beta$ overproduction in a mouse model of Alzheimer's disease. Eur J Neurosci 37:1896-1902.

Graham WV, Bonito-Oliva A, Sakmar TP (2017) Update on Alzheimer's disease therapy and prevention strategies. Annu Rev Med 68:413-430.

Griffiths I, Klugmann M, Anderson T, Yool D, Thomson C, Schwab MH, Schneider A, Zimmermann F, McCulloch M, Nadon N, Nave KA (1998) Axonal swellings and degeneration in mice lacking the major proteolipid of myelin. Science 280:1610-1613.

Guillemin GJ, Smythe G, Takikawa O, Brew BJ (2005) Expression of indoleamine 2,3-dioxygenase and production of quinolinic acid by human microglia, astrocytes, and neurons. Glia 49:15-23.

Hait NC, Wise LE, Allegood JC, O'Brien M, Avni D, Reeves TM, Knapp PE, Lu J, Luo C, Miles MF, Milstien S, Lichtman AH, Spiegel S (2014) Active, phosphorylated fingolimod inhibits histone deacetylases and facilitates fear extinction memory. Nat Neurosci 17:971-980.

Han X, Holtzman DM, McKeel DW Jr, Kelley J, Morris JC (2002) Substantial sulfatide deficiency and ceramide elevation in very early Alzheimer's disease: potential role in disease pathogenesis. J Neurochem 82:809-818.

He X, Huang Y, Li B, Gong CX, Schuchman EH (2010) Deregulation of sphingolipid metabolism in Alzheimer's disease. Neurobiol Aging 31: $398-408$.

Holtzman DM, Morris JC, Goate AM (2011) Alzheimer's disease: the challenge of the second century. Sci Transl Med 3:77 $\mathrm{sr} 1$.

Ittner LM, Fath T, Ke YD, Bi M, van Eersel J, Li KM, Gunning P, Götz J (2008) Parkinsonism and impaired axonal transport in a mouse model of frontotemporal dementia. Proc Natl Acad Sci U SA 105:15997-16002.

Ittner A, Gladbach A, Bertz J, Suh LS, Ittner LM (2014) p38 MAP kinasemediated NMDA receptor-dependent suppression of hippocampal hypersynchronicity in a mouse model of Alzheimer's disease. Acta Neuropathol Commun 2:149.

Ittner A, Chua SW, Bertz J, Volkerling A, van der Hoven J, Gladbach A, Przybyla M, Bi M, van Hummel A, Stevens CH, Ippati S, Suh LS, Macmillan A, Sutherland G, Kril JJ, Silva AP, Mackay JP, Poljak A, Delerue F, Ke YD, Ittner LM (2016) Site-specific phosphorylation of tau inhibits amyloid-beta toxicity in Alzheimer's mice. Science 354:904-908.

Jaillard C, Harrison S, Stankoff B, Aigrot MS, Calver AR, Duddy G, Walsh FS, Pangalos MN, Arimura N, Kaibuchi K, Zalc B, Lubetzki C (2005) Edg8/ S1P5: an oligodendroglial receptor with dual function on process retraction and cell survival. J Neurosci 25:1459-1469.

Jin LW, Shie FS, Maezawa I, Vincent I, Bird T (2004) Intracellular accumulation of amyloidogenic fragments of amyloid-beta precursor protein in neurons with Niemann-Pick type $\mathrm{C}$ defects is associated with endosomal abnormalities. Am J Pathol 164:975-985.

Jonsson T, Atwal JK, Steinberg S, Snaedal J, Jonsson PV, Bjornsson S, Stefansson H, Sulem P, Gudbjartsson D, Maloney J, Hoyte K, Gustafson A, Liu Y, Lu Y, Bhangale T, Graham RR, Huttenlocher J, Bjornsdottir G, Andreassen OA, Jönsson EG, et al. (2012) A mutation in APP protects against Alzheimer's disease and age-related cognitive decline. Nature 488:96-99.

Jung M, Krämer E, Grzenkowski M, Tang K, Blakemore W, Aguzzi A, Khazaie K, Chlichlia K, von Blankenfeld G, Kettenmann H, et al. (1995) Lines of murine oligodendroglial precursor cells immortalized by an activated neu tyrosine kinase show distinct degrees of interaction with axons in vitro and in vivo. Eur J Neurosci 7:1245-1265.

Kajimoto T, Okada T, Yu H, Goparaju SK, Jahangeer S, Nakamura S (2007) Involvement of sphingosine-1-phosphate in glutamate secretion in hippocampal neurons. Mol Cell Biol 27:3429-3440.

Karch CM, Goate AM (2015) Alzheimer's disease risk genes and mechanisms of disease pathogenesis. Biol Psychiatry 77:43-51.

Karl T, Bhatia S, Cheng D, Kim WS, Garner B (2012) Cognitive phenotyping of amyloid precursor protein transgenic J20 mice. Behav Brain Res 228:392-397.

Kim HJ, Miron VE, Dukala D, Proia RL, Ludwin SK, Traka M, Antel JP, Soliven B (2011) Neurobiological effects of sphingosine 1-phosphate receptor modulation in the cuprizone model. FASEB J 25:1509-1518.

Lee H, Lee JK, Park MH, Hong YR, Marti HH, Kim H, Okada Y, Otsu M, Seo EJ, Park JH, Bae JH, Okino N, He X, Schuchman EH, Bae JS, Jin HK
(2014) Pathological roles of the VEGF/SphK pathway in Niemann-Pick type $C$ neurons. Nat Commun 5:5514.

Lei M, Shafique A, Shang K, Couttas TA, Zhao H, Don AS, Karl T (2017) Contextual fear conditioning is enhanced in mice lacking functional sphingosine kinase 2. Behav Brain Res 333:9-16.

Lima S, Milstien S, Spiegel S (2017) Sphingosine and sphingosine kinase 1 involvement in endocytic membrane trafficking. J Biol Chem 292:3074-3088.

Lu F, Liang Q, Abi-Mosleh L, Das A, De Brabander JK, Goldstein JL, Brown MS (2015) Identification of NPC1 as the target of U18666A, an inhibitor of lysosomal cholesterol export and Ebola infection. eLife 4:e12177.

Maas DA, Vallès A, Martens GJM (2017) Oxidative stress, prefrontal cortex hypomyelination and cognitive symptoms in schizophrenia. Transl Psychiatry 7:e1171.

Matyash V, Liebisch G, Kurzchalia TV, Shevchenko A, Schwudke D (2008) Lipid extraction by methyl-tert-butyl ether for high-throughput lipidomics. J Lipid Res 49:1137-1146.

Mizugishi K, Yamashita T, Olivera A, Miller GF, Spiegel S, Proia RL (2005) Essential role for sphingosine kinases in neural and vascular development. Mol Cell Biol 25:11113-11121.

Morel E, Chamoun Z, Lasiecka ZM, Chan RB, Williamson RL, Vetanovetz C, Dall'Armi C, Simoes S, Point Du Jour KS, McCabe BD, Small SA, Di Paolo G (2013) Phosphatidylinositol-3-phosphate regulates sorting and processing of amyloid precursor protein through the endosomal system. Nat Commun 4:2250.

Mucke L, Masliah E, Yu GQ, Mallory M, Rockenstein EM, Tatsuno G, Hu K, Kholodenko D, Johnson-Wood K, McConlogue L (2000) High-level neuronal expression of $A \beta 1-42$ in wild-type human amyloid protein precursor transgenic mice: synaptotoxicity without plaque formation. J Neurosci 20:4050-4058.

Nixon RA (2017) Amyloid precursor protein and endosomal-lysosomal dysfunction in Alzheimer's disease: inseparable partners in a multifactorial disease. FASEB J 31:2729-2743.

Nordestgaard LT, Tybjærg-Hansen A, Nordestgaard BG, Frikke-Schmidt R (2015) Loss-of-function mutation in ABCA1 and risk of Alzheimer's disease and cerebrovascular disease. Alzheimers Dement 11:1430-1438.

Nuriel T, Peng KY, Ashok A, Dillman AA, Figueroa HY, Apuzzo J, Ambat J, Levy E, Cookson MR, Mathews PM, Duff KE (2017) The endosomallysosomal pathway is dysregulated by APOE4 expression in vivo. Front Neurosci 11:702.

Palop JJ, Chin J, Roberson ED, Wang J, Thwin MT, Bien-Ly N, Yoo J, Ho KO, Yu GQ, Kreitzer A, Finkbeiner S, Noebels JL, Mucke L (2007) Aberrant excitatory neuronal activity and compensatory remodeling of inhibitory hippocampal circuits in mouse models of Alzheimer's disease. Neuron 55:697-711.

Pfeilschifter W, Czech-Zechmeister B, Sujak M, Mirceska A, Koch A, Rami A, Steinmetz H, Foerch C, Huwiler A, Pfeilschifter J (2011) Activation of sphingosine kinase 2 is an endogenous protective mechanism in cerebral ischemia. Biochem Biophys Res Commun 413:212-217.

Price JL, McKeel DW Jr, Buckles VD, Roe CM, Xiong C, Grundman M, Hansen LA, Petersen RC, Parisi JE, Dickson DW, Smith CD, Davis DG, Schmitt FA, Markesbery WR, Kaye J, Kurlan R, Hulette C, Kurland BF, Higdon R, Kukull W, Morris JC (2009) Neuropathology of nondemented aging: presumptive evidence for preclinical Alzheimer disease. Neurobiol Aging 30:1026-1036.

Riganti L, Antonucci F, Gabrielli M, Prada I, Giussani P, Viani P, Valtorta F, Menna E, Matteoli M, Verderio C (2016) Sphingosine-1-phosphate (S1P) impacts presynaptic functions by regulating synapsin I localization in the presynaptic compartment. J Neurosci 36:4624-4634.

Rosen H, Stevens RC, Hanson M, Roberts E, Oldstone MB (2013) Sphingosine-1-phosphate and its receptors: structure, signaling, and influence. Annu Rev Biochem 82:637-662.

Saito Y, Suzuki K, Nanba E, Yamamoto T, Ohno K, Murayama S (2002) Niemann-Pick type C disease: accelerated neurofibrillary tangle formation and amyloid beta deposition associated with apolipoprotein E epsilon 4 homozygosity. Ann Neurol 52:351-355.

Selnes P, Fjell AM, Gjerstad L, Bjørnerud A, Wallin A, Due-Tønnessen P, Grambaite R, Stenset V, Fladby T (2012) White matter imaging changes in subjective and mild cognitive impairment. Alzheimers Dement 8:S112S121.

Shen H, Giordano F, Wu Y, Chan J, Zhu C, Milosevic I, Wu X, Yao K, Chen B, Baumgart T, Sieburth D, De Camilli P (2014) Coupling between endocytosis and sphingosine kinase 1 recruitment. Nat Cell Biol 16:652-662. 
Simons M, Nave KA (2016) Oligodendrocytes: myelination and axonal support. Cold Spring Harb Perspect Biol 8:a020479.

Stedehouder J, Kushner SA (2017) Myelination of parvalbumin interneurons: a parsimonious locus of pathophysiological convergence in schizophrenia. Mol Psychiatry 22:4-12.

Takasugi N, Sasaki T, Suzuki K, Osawa S, Isshiki H, Hori Y, Shimada N, Higo T, Yokoshima S, Fukuyama T, Lee VM, Trojanowski JQ, Tomita T, Iwatsubo T (2011) BACE1 activity is modulated by cell-associated sphingosine-1-phosphate. J Neurosci 31:6850-6857.

Tamboli IY, Hampel H, Tien NT, Tolksdorf K, Breiden B, Mathews PM, Saftig P, Sandhoff K, Walter J (2011) Sphingolipid storage affects autophagic metabolism of the amyloid precursor protein and promotes $\mathrm{A} \beta$ generation. J Neurosci 31:1837-1849.

Tort AB, Komorowski RW, Manns JR, Kopell NJ, Eichenbaum H (2009) Theta-gamma coupling increases during the learning of item-context associations. Proc Natl Acad Sci U S A 106:20942-20947.

Tort AB, Komorowski R, Eichenbaum H, Kopell N (2010) Measuring phase-amplitude coupling between neuronal oscillations of different frequencies. J Neurophysiol 104:1195-1210.

van der Kant R, Goldstein LS (2015) Cellular functions of the amyloid precursor protein from development to dementia. Dev Cell 32:502-515.

van der Kant R, Langness VF, Herrera CM, Williams DA, Fong LK, Leestemaker Y, Steenvoorden E, Rynearson KD, Brouwers JF, Helms JB, Ovaa H, Giera M, Wagner SL, Bang AG, Goldstein LSB (2019) Cholesterol metabolism is a druggable axis that independently regulates tau and amyloid- $\beta$ in iPSC-derived Alzheimer's disease neurons. Cell Stem Cell 24:363-375.e9.

Verret L, Mann EO, Hang GB, Barth AM, Cobos I, Ho K, Devidze N, Masliah E, Kreitzer AC, Mody I, Mucke L, Palop JJ (2012) Inhibitory interneuron deficit links altered network activity and cognitive dysfunction in Alzheimer model. Cell 149:708-721.

Voineskos AN, Felsky D, Kovacevic N, Tiwari AK, Zai C, Chakravarty MM, Lobaugh NJ, Shenton ME, Rajji TK, Miranda D, Pollock BG, Mulsant BH, McIntosh AR, Kennedy JL (2013) Oligodendrocyte genes, white matter tract integrity, and cognition in schizophrenia. Cereb Cortex 23:2044-2057.

Wallin A, Gottfries CG, Karlsson I, Svennerholm L (1989) Decreased myelin lipids in Alzheimer's disease and vascular dementia. Acta Neurol Scandinavica 80:319-323.

Wong JW, Abuhusain HJ, McDonald KL, Don AS (2012) MMSAT: automated quantification of metabolites in selected reaction monitoring experiments. Anal Chem 84:470-474.

Xu J, Chen S, Ahmed SH, Chen H, Ku G, Goldberg MP, Hsu CY (2001) Amyloid- $\beta$ peptides are cytotoxic to oligodendrocytes. J Neurosci 21:RC118.

Yassine HN, Feng Q, Chiang J, Petrosspour LM, Fonteh AN, Chui HC, Harrington MG (2016) ABCA1-mediated cholesterol efflux capacity to cerebrospinal fluid is reduced in patients with mild cognitive impairment and Alzheimer's disease. J Am Heart Assoc 5:e002886.

Zhuang L, Sachdev PS, Trollor JN, Reppermund S, Kochan NA, Brodaty H, Wen W (2013) Microstructural white matter changes, not hippocampal atrophy, detect early amnestic mild cognitive impairment. PLoS One 8:e58887. 